\title{
Muscle-specific knockout of PKC- $\lambda$ impairs glucose transport and induces metabolic and diabetic syndromes
}

\author{
Robert V. Farese,1,2,3 Mini P. Sajan,1,2,3 Hong Yang, 1,2,3 Pengfei Li, 1,3 Steven Mastorides, ${ }^{1}$ \\ William R. Gower Jr., 1,3 Sonali Nimal, 1,2,3 Cheol Soo Choi, ${ }^{4}$ Sheene Kim, ${ }^{4}$ Gerald I. Shulman, ${ }^{4}$ \\ C. Ronald Kahn, ${ }^{5}$ Ursula Braun, ${ }^{6,7}$ and Michael Leitges ${ }^{6,7}$

\begin{abstract}
1James A. Haley Veterans Medical Center, Tampa, Florida, USA. ${ }^{2}$ Roskamp Institute, Sarasota, Florida, USA. ${ }^{3}$ Department of Internal Medicine and Department of Molecular Medicine, University of South Florida College of Medicine, Tampa, Florida, USA. ${ }^{4}$ Department of Internal Medicine, Yale University School of Medicine, New Haven, Connecticut, USA. ${ }^{5} \mathrm{~J}$ oslin Research Foundation and Harvard Medical School, Boston, Massachusetts, USA. ${ }^{6}$ Division of Nephrology, Department of Medicine, Hannover Medical School, Hannover, Germany. ${ }^{7 B i o t e c h n o l o g y ~ C e n t r e ~ o f ~ O s l o, ~ O s l o, ~ N o r w a y . ~}$
\end{abstract}

\begin{abstract}
Obesity, the metabolic syndrome, and type 2 diabetes mellitus (T2DM) are major global health problems. Insulin resistance is frequently present in these disorders, but the causes and effects of such resistance are unknown. Here, we generated mice with muscle-specific knockout of the major murine atypical PKC (aPKC), PKC- $\lambda$, a postulated mediator for insulin-stimulated glucose transport. Glucose transport and translocation of glucose transporter 4 (GLUT4) to the plasma membrane were diminished in muscles of both homozygous and heterozygous PKC- $\lambda$ knockout mice and were accompanied by systemic insulin resistance; impaired glucose tolerance or diabetes; islet $\beta$ cell hyperplasia; abdominal adiposity; hepatosteatosis; elevated serum triglycerides, FFAs, and LDL-cholesterol; and diminished HDL-cholesterol. In contrast to the defective activation of muscle aPKC, insulin signaling and actions were intact in muscle, liver, and adipocytes. These findings demonstrate the importance of aPKC in insulin-stimulated glucose transport in muscles of intact mice and show that insulin resistance and resultant hyperinsulinemia owing to a specific defect in muscle aPKC is sufficient to induce abdominal obesity and other lipid abnormalities of the metabolic syndrome and T2DM. These findings are particularly relevant because humans who have obesity, impaired glucose tolerance, and T2DM reportedly have defective activation and/or diminished levels of muscle aPKC.
\end{abstract}

\section{Introduction}

Glucose transport is rate-limiting for glucose metabolism in most tissues. In muscle, the major tissue for whole-body glucose disposal, defects in insulin-stimulated glucose transport are observed in obesity; the metabolic syndrome, with associated abdominal obesity, hyperlipidemia, and impaired glucose tolerance (IGT); and type 2 diabetes mellitus (T2DM).

Factors that mediate insulin stimulation of glucose transport are still poorly defined. Studies using inhibitory agents in cultured myocytes and adipocytes suggest that insulin-stimulated glucose transport is regulated by atypical PKCs (aPKCs), PKC- $\zeta$ and PCK- $\lambda$ (1-7), and by PKB/Akt (8-12), operating downstream of PI3K. There is, however, little evidence from gene-targeting studies to implicate specific isoforms of aPKC and PKB that are required for insulin-stimulated glucose transport in intact muscle. Total-body KO of PKB- $\alpha /$ Akt1 does not alter glucose homeostasis (13), and total-body KO of PKB- $\beta /$ Akt2 produces a diabetic state, characterized by markedly defective hepatic glucose metabolism and a partial decrease in insulin-stimulated glucose transport in muscle that is evident only at submaximal insulin concentrations (14). Total-body KO of PKC- $\lambda$, the major murine aPKC, is embryonic

Nonstandard abbreviations used: aPKC, atypical PKC; AS160, Akt substrate 160; 2-DG, 2-deoxyglucose; FAS, fatty acid synthase; GLUT, glucose transporter; GSK, glycogen synthase kinase; HGP, hepatic glucose production; IGT, impaired glucose tolerance; IRS, insulin receptor substrate; $\mathrm{MCK}$, muscle creatine kinase; $\mathrm{PIP}_{3}$, phosphatidylinositol-3,4,5,-( $\left(\mathrm{PO}_{4}\right)_{3} ; \mathrm{T} 2 \mathrm{DM}$, type 2 diabetes mellitus.

Conflict of interest: The authors have declared that no conflict of interest exists. Citation for this article: J. Clin. Invest. 117:2289-2301 (2007). doi:10.1172/JCI31408 lethal, and, despite reports of liver-specific (15) and pancreatic $\beta$ cell-specific (16) PKC- $\lambda$ KO, there are no reports to our knowledge of muscle-specific PKC- $\lambda$ KO. Information on effects of this deficiency in muscle aPKC is particularly relevant, because aPKC levels are diminished and/or poorly activated in muscles of humans who have obesity $(17,18), \operatorname{IGT}(19,20)$, and $\operatorname{T2DM}(17,20,21)$.

Here, we report on a muscle-specific PKC- $\lambda$ KO created by breeding mice harboring Cre recombinase transgene controlled by a muscle creatine kinase (MCK) promotor/enhancer with mice carrying a targeted PKC- $\lambda$ allele with loxP sites flanking an essential exon located at nucleotides 110-233; details of the floxed PKC- $\lambda$ construct were described previously (22). In these mice, we directly tested the hypothesis that aPKC is required for glucose transport effects of insulin; moreover, we examined the metabolic consequences of defects in aPKC availability/activation and glucose transport occurring specifically in muscle. We found that insulin-stimulated glucose transport was markedly impaired in heart muscle of $\mathrm{KO}$ mice in which aPKC levels were diminished. Moreover, this isolated defect in muscle glucose transport was accompanied by systemic insulin resistance, glucose intolerance, abdominal obesity, hyperlipidemia, and hepatosteosis, i.e., features of metabolic syndrome.

\section{Results}

Glucose transport in muscles of homozygous KO mice. Total aPKC and PKC- $\lambda$ levels were markedly diminished $(\sim 80 \%)$ in vastus lateralis and heart muscles of mice with homozygous muscle-specific PKC- $\lambda$ $\mathrm{KO}\left(\mathrm{Cre}^{+} \mathrm{lox} \mathrm{P}^{+/+}\right.$; Figure 1, A and B, and Figure 2A). This aPKC deficiency was accompanied by marked decreases in muscle uptake of 

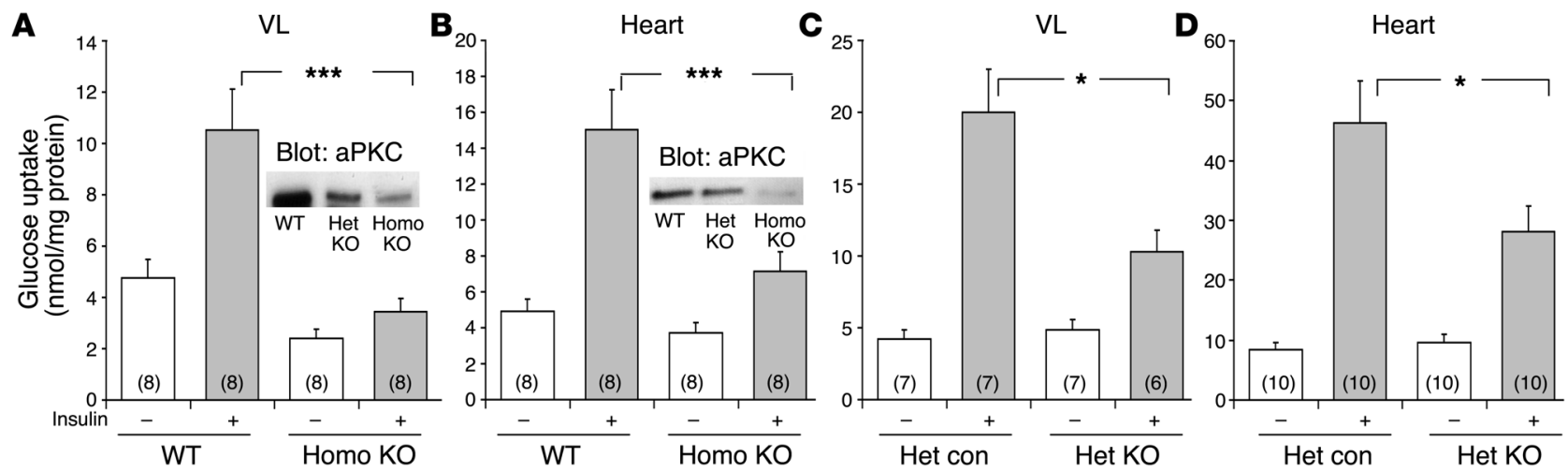

E

EDL

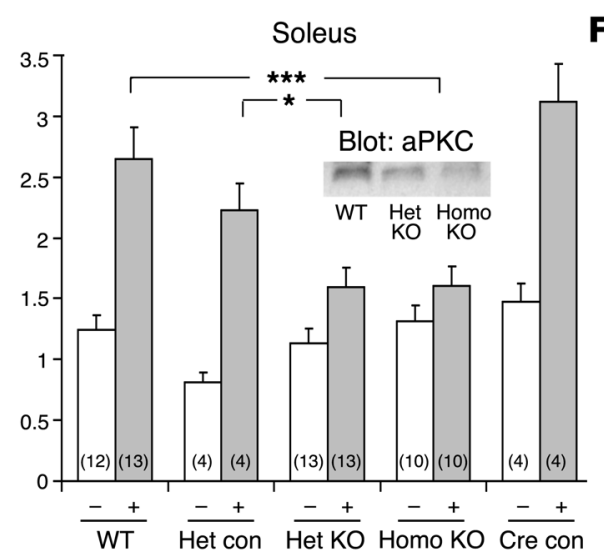

F PM GLUT4
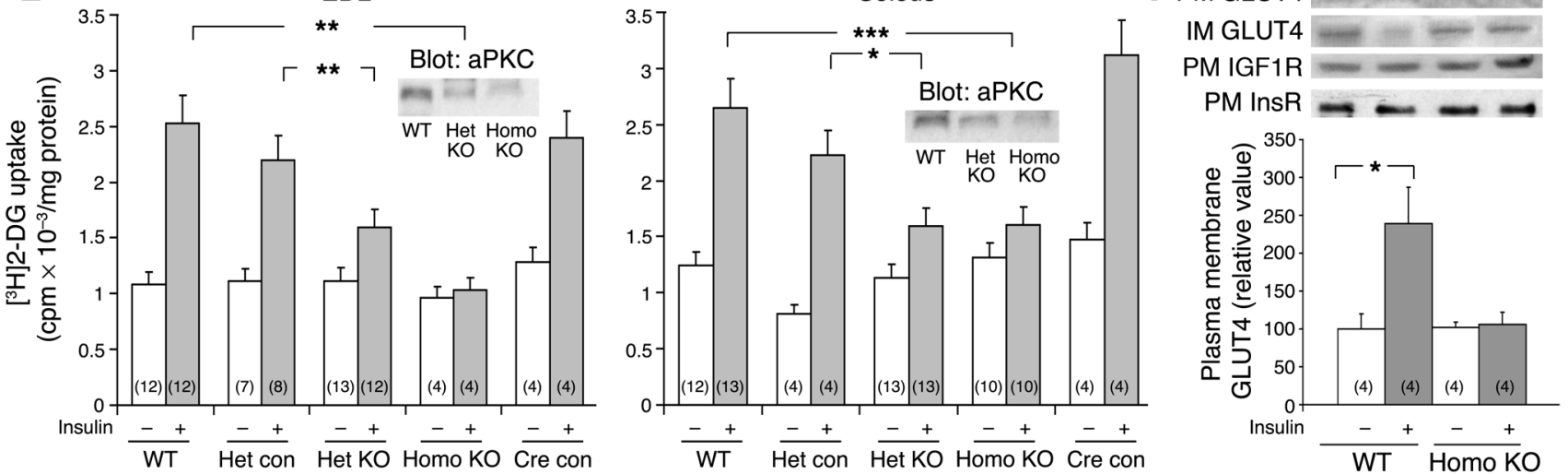

Figure 1

Effects of homozygous and heterozygous muscle-specific KO of PKC- $\lambda$ on basal and insulin-stimulated glucose transport in vivo (A-D), glucose transport in vitro (E), and plasma membrane (PM) GLUT4 levels (F). Equal numbers of 5-month-old male and female mice were grouped (results were indistinguishable and therefore pooled), and after an overnight fast, glucose transport and GLUT4 translocation were measured. Glucose uptake was measured in vastus lateralis (VL) and heart muscle during 10 minutes insulin or vehicle treatment (A-D). (E) Glucose transport was measured in isolated extensor digitorum longus (EDL) and soleus muscles obtained from male mice. (F) Vastus lateralis and gastrocnemius muscles were used to prepare plasma membranes. Values are mean \pm SEM. $n$ for each group is shown in parentheses. Insets show immunoreactive levels of total cellular aPKC (A, B, and E) or plasma membrane and internal membrane (IM) GLUT4 levels or IGF1 receptor (IGF1R) and insulin receptor (InsR) $\beta$ subunit levels as markers to show equal plasma membrane loading (F) in WT (Cre-lox $P^{-/-}$), heterozygous KO

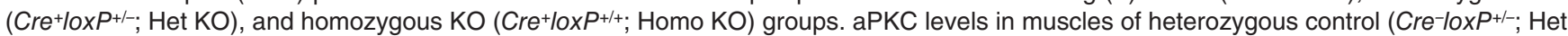
con) and Cre control (Cre+lox $P^{-1-}$; Cre con) mice were the same as in WT mice (not shown). ${ }^{*}<0.05 ;{ }^{* *} P<0.01 ;{ }^{* \star *} P<0.001$.

glucose, both basally and during insulin treatment, in vivo (Figure $1, A$ and B). Small residual effects of insulin on glucose transport in muscles of $\mathrm{KO}$ mice may be mediated by PKC- $\zeta$, a minor aPKC in mouse muscle (6), the levels of which were unaltered in muscles of $\mathrm{KO}$ mice (Figure 2A).

Levels of aPKC and insulin-stimulated $\left[{ }^{3} \mathrm{H}\right] 2$-deoxyglucose $\left(\left[{ }^{3} \mathrm{H}\right] 2-\mathrm{DG}\right)$ uptake in vitro were also diminished in slow-twitch soleus and fast-twitch extensor digitorum longus muscles of homozygous KO mice (Figure 1E). Uptake of $\left[{ }^{3} \mathrm{H}\right] 2-\mathrm{DG}$ was not influenced by the presence of MCK-controlled Cre recombinase in the absence of loxP sites in PKC- $\lambda$, i.e., in $\mathrm{Cre}^{+} l o x \mathrm{P}^{-/-}$mice (Figure 1E).

Glucose transport in muscles of heterozygous $\mathrm{KO}$ mice. In heterozygous $\mathrm{KO}$ mice $\left(\mathrm{Cre}^{+} \mathrm{lo} x \mathrm{P}^{+/-}\right)$, aPKC and PKC- $\lambda$ levels were partially diminished ( $40 \%$; Figure 1, A and B, and Figure $2 \mathrm{~B}$ ), and insulin-stimulated increases in glucose and 2-DG uptake were diminished by $50 \%-60 \%$ in vastus lateralis and heart muscles in vivo (Figure $1, \mathrm{C}$ and D) as well as in soleus and extensor digitorum longus muscles in vitro (Figure $1 \mathrm{E}$ ). Note that here we compared heterozygous KO mice with Cre recombinase-negative, loxP-positive heterozygous control mice $\left(\mathrm{Cre}^{-} \mathrm{lox} \mathrm{P}^{+/-}\right)$, in which muscle aPKC levels, insulinstimulated glucose transport, and phenotypic characteristics were indistinguishable from those of WT mice $\left(\mathrm{Cre}^{-} \mathrm{lox} \mathrm{P}^{-/-}\right)$. Thus, defects in glucose transport and metabolism were dependent upon combined presence of MCK-dependent Cre recombinase and PKC- $\lambda$ loxP sites, i.e., reflecting muscle aPKC deficiency.

Glucose transporter 4 translocation in muscles of $\mathrm{KO}$ mice. Insulin provoked increases in plasma membrane content of glucose transporter 4 (GLUT4) in muscles of WT mice, but not homozygous $\mathrm{KO}$ mice (Figure $1 \mathrm{~F}$ ). Also note the reciprocal changes in GLUT4 levels in internal membranes (i.e., insulin-induced decreases in WT, but not $\mathrm{KO}$, mice) and the comparable plasma membrane levels of $\beta$ subunits of IGF-1 and insulin receptor in WT and $\mathrm{KO}$ mice (Figure $1 \mathrm{~F}$ ).

Activation of aPKC, $P K B$, and insulin receptor substrate 1-dependent $P I 3 K$ in muscles of KO mice. Total immunoprecipitable aPKC (PKC- $\lambda$ plus PKC- $\zeta$ ) activity was markedly diminished in muscles of homozygous and heterozygous KO mice (Figure 3A). Although we were unable to separately measure PKC- $\lambda$ and $\mathrm{PKC}-\zeta$ activities, 
A

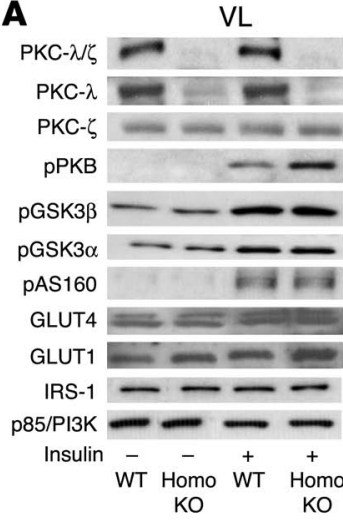

Heart

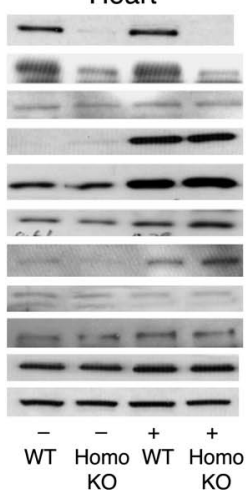

B
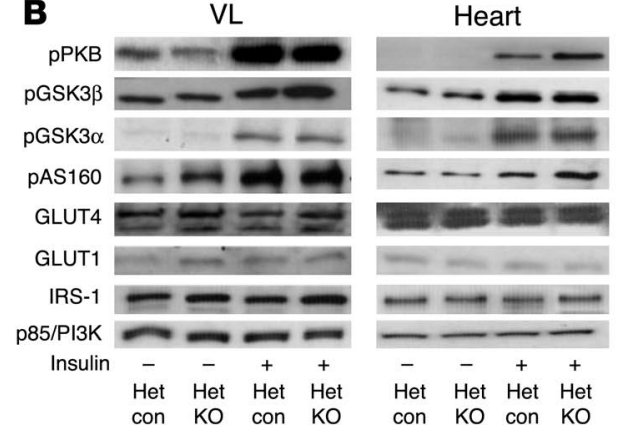

Figure 2

Effects of homozygous and heterozygous muscle-specific KO of PKC- $\lambda$ on levels of insulin-sensitive signaling factors and glucose transporters in skeletal and heart muscle. Muscles were obtained from mice treated as described in Figure 1, A-D. Shown are representative immunoblots of muscle factors from basal and insulin-stimulated WT, heterozygous control, homozygous $\mathrm{KO}$, and heterozygous $\mathrm{KO}$ mice. In A, VL and heart muscle of WT and homozygous KO mice, treated with or without insulin were compared. In B, VL and heart muscle of WT and heterozygous KO mice were compared. p-, phosphorylated. See Figure 1 for comparison of aPKC levels amongst groups.

the low total aPKC activity presumably reflected the greater abundance of PKC- $\lambda$ in mouse muscle (6). Lower-than-expected muscle aPKC activity in heterozygous $\mathrm{KO}$ mice may reflect poor aPKC responsiveness to phosphatidylinositol-3,4,5,-( $\left.\mathrm{PO}_{4}\right)_{3}\left(\mathrm{PIP}_{3}\right)$, which increased activity of aPKC immunoprecipitated from muscles of heterozygous control mice, but not heterozygous $\mathrm{KO}$ mice (Figure $3 \mathrm{~B})$. Such aPKC unresponsiveness to $\mathrm{PIP}_{3}$ also occurs in some insulin-resistant humans and rodents (e.g., refs. 18, 20, 23).

Unlike aPKC activation, insulin-stimulated PKB activity and Ser473 phosphorylation in muscle increased substantially in homozygotes but was essentially normal in heterozygotes (Figure 2 , A and B, and Figure $3 \mathrm{~A}$ ). Phosphorylation of PKB substrates glycogen synthase kinase $3 \alpha$ (GSK3 $\alpha$ ), GSK3 $\beta$, and Akt substrate 160 (AS160; Figure 2, A and B) and insulin receptor substrate 1-dependent (IRS-1-dependent) PI3K activity (Figure 3A, insets) was also intact in muscles of KO mice. Thus, except for defects in aPKC activation, insulin signaling mechanisms were intact or enhanced in $\mathrm{KO}$ muscle.

Activation of aPKC, PKB, and IRS-1-dependent and IRS-2-dependent $P I 3 K$ in livers of $K O$ mice. In contrast to what we observed in muscle, the livers of homozygous and heterozygous $\mathrm{KO}$ mice showed aPKC levels and insulin-stimulated aPKC activities comparable to those of WT and heterozygous control mice (Figure 4). Basal aPKC activity in heterozygous KO liver trended upward, perhaps reflecting hyperinsulinemia (see Serum glucose and insulin levels in $\mathrm{KO}$ mice). On the other hand, insulin-stimulated activity and Ser473 phosphorylation of hepatic PKB, a major regulator of hepatic glucose metabolism and fasting blood glucose levels, was markedly enhanced in homozygotes but not in heterozygotes; in the latter, PKB activity and phosphorylation were diminished (Figure 4). The mechanism underlying increased hepatic PKB phosphorylation and activation in homozygotes is uncertain, but it did not appear to be the result of changes in IRS-1- or IRS-2dependent PI3K activation (Figure 4).

Serum glucose and insulin levels in KO mice. Even though insulinstimulated glucose transport in muscle was markedly decreased,

comparable to, or more severe than, those observed in homozygotes. In addition, fasting blood glucose levels were mildly but significantly increased ( $20 \%-25 \%)$ during insulin and glucose tolerance tests in heterozygotes, and serum insulin levels increased to a greater extent during glucose tolerance tests in heterozygotes (Figure 5). Also, modestly increasing dietary fat content from $5 \%$ to $10 \%$ for 2 months increased blood glucose levels in both WT and heterozygous KO mice, but differences remained apparent at all time points, including fasting levels, during glucose tolerance testing (Figure 6B). Moreover, food intake increased by $20 \%$, a significant difference, in heterozygotes consuming standard chow. Dietary intake in homozygotes was not appreciably different from that of WT mice (data not shown). In summary, heterozygotes apparently developed an obesity/diabetes syndrome that was abetted by dietary excess.

Interestingly, serum glucose and insulin levels were higher in male $\mathrm{KO}$ mice relative to female $\mathrm{KO}$ mice (Figures 5 and 6), whereas abdominal obesity and serum lipid abnormalities were at least as prominent in female $\mathrm{KO}$ mice (see Serum glucose and insulin levels in $\mathrm{KO}$ mice). The reasons for these differences were unclear, as we did not discern sex-related differences in muscle glucose uptake or insulin signaling to PKB and aPKC in liver or to PKB in muscle.

Peripheral and hepatic insulin sensitivity and resistance in byperinsulinemic englycemic clamp studies. At the time of the clamp, mean fasting plasma glucose levels were not significantly different among the WT, heterozygous $\mathrm{KO}$, and homozygous $\mathrm{KO}$ groups (Figure 7A). To evaluate the effects of muscle-specific deficiency of PKC- $\lambda$ on insulin-stimulated glucose metabolism in vivo, 2-hour hyperinsulinemic-euglycemic clamps were conducted in conscious male mice. During the clamp, insulin was infused at a constant rate $(18 \mathrm{pmol} / \mathrm{kg} / \mathrm{min})$ to raise plasma insulin within a physiological range, and plasma glucose was clamped at approximately $115 \mathrm{mg} / \mathrm{dl}$ (Figure 7A). Glucose infusion rates in heterozygous and homozygous $\mathrm{KO}$ mice needed to maintain euglycemia were identical, but consistently lower than that needed in WT mice (Figure 7B). This whole-body insulin resistance was predominantly accounted for by decreases in insulin-stimulated 
A
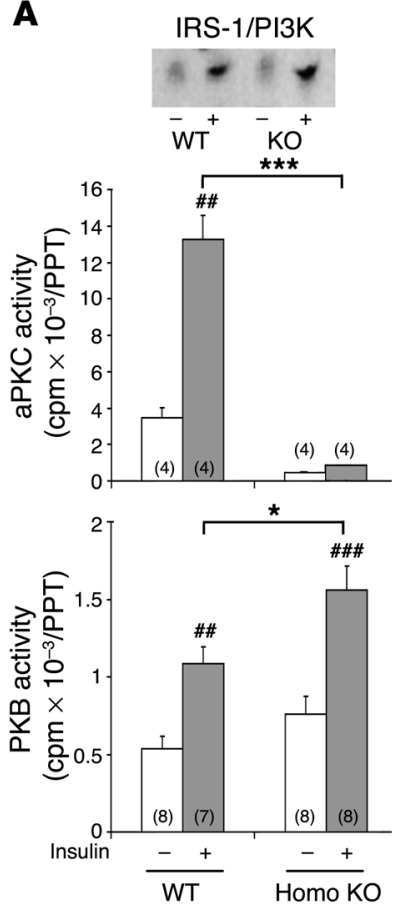

B

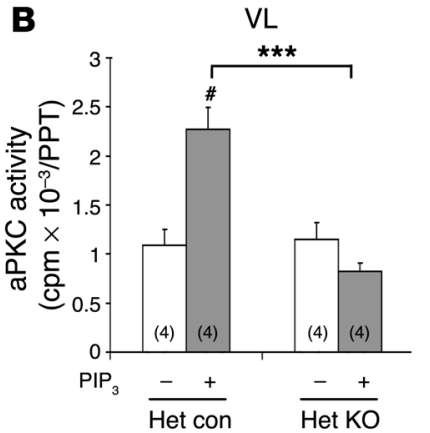

VL
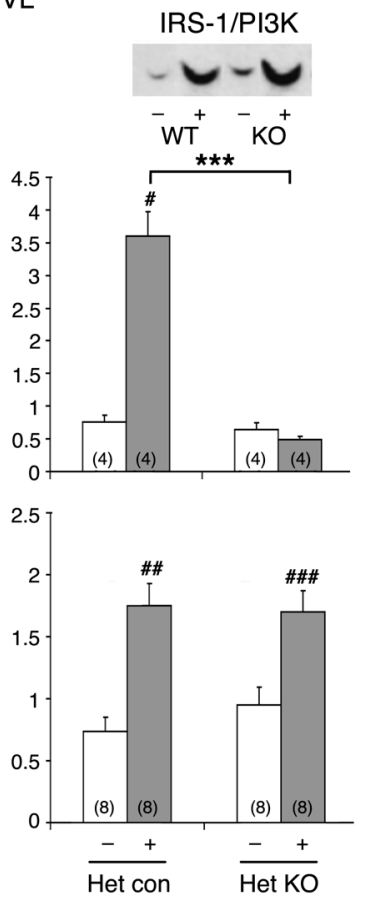

\section{Figure 3}

Insulin signaling in muscle of homozygous and heterozygous $\mathrm{KO}$ mice. (A) Effects of homozygous and heterozygous muscle-specific $K O$ of PKC- $\lambda$ on basal and in vivo insulin-stimulated activities of aPKC, $\mathrm{PKB}$, and IRS-1-dependent PI3K in vastus lateralis muscles of homozygous $\mathrm{KO}$ versus WT and heterozygous $\mathrm{KO}$ versus heterozygous control mice. Experiments were conducted as described in Figure $1, \mathrm{~A}-\mathrm{D}$. Insets show representative autoradiograms of basal $(-)$ and insulin-stimulated (+) IRS-1-dependent PI3K (IRS-1/PI3K) activity, i.e., ${ }_{32} \mathrm{P}-\mathrm{PI}-3-\mathrm{PO}_{4}$ resolved by thin-layer chromatography. (B) Effects of $\mathrm{PKC}-\lambda \mathrm{KO}$ on in vitro $\mathrm{PIP}_{3}$-stimulated activity in aPKC immunoprecipitates obtained from basal (not stimulated by insulin) vastus lateralis muscles of heterozygous control and heterozygous $\mathrm{KO}$ mice. Note that absolute values of kinase assays varied considerably in different assays (e.g., aPKC values herein), most likely reflecting interassay differences of ATP-specific activity and/or enzyme recoveries or activities in immunoprecipitates; thus, absolute values can only be compared within the same assay. Values are mean \pm SEM. $n$ for each

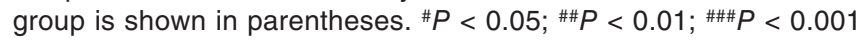
versus non-insulin-stimulated group of the same genotype (ANOVA). ${ }^{\star} P<0.05 ;{ }^{* \star} P<0.001$ (ANOVA).

Alterations in hepatic lipid metabolism and hepatosteatosis in $\mathrm{KO}$ mice. Along with greater abdominal obesity and hyperlipidemia in heterozygotes, expression of hepatic SREBP-1c and fatty acid synthase (FAS) - which, together with other SREBP-1c-dependent enzymes, regulate lipid synthesis - was increased to a greater extent in fed heterozygotes than in homozygotes and WT mice (Figure 9A). Increases in SREBP$1 \mathrm{c}$ mRNA in fed heterozygotes were accompanied by increases in the active nuclear SREBP-1c fragment (Figure 9A, inset).

In addition to increased expression of hepatic lipid-synthesizing enzymes, fat droplet and triglyceride contents were increased in livers of homozygous and heterozygous $\mathrm{KO}$ mice, even in those consuming a low-fat diet ( $5 \%$ by weight; Figure 9B); here again, hepatosteatosis was more pronounced in heterozygotes.

Intact glucose transport in adipose tissue and adipocytes of $\mathrm{KO}$ mice. Total aPKC levels were normal in adipose tissues of mice with muscle-specific PKC- $\lambda$ KO (Figure 10A). Moreover, insulin-stimulated glucose uptake and transport was intact in whole adipose tissue studied in vivo (Figure 10A) and in isolated adipocytes (Figure 10B) of homozygous and heterozygous KO mice. Conversely, insulin-stimulated glucose transport in adipocytes of mice with adipocyte-specific PKC- $\lambda$ KO was markedly impaired (our unpublished observations).

Serum adipokines. In association with increased abdominal adiposity, serum leptin levels increased in heterozygous and homozygous KO mice (Figure 10C). On the other hand, whereas serum resistin levels were not significantly altered, serum adiponectin levels were increased in homozygotes, but not in heterozygotes (Figure 10C).

Islet $\beta$ cell mass. Islet $\beta$ cell mass was markedly expanded in heterozygotes and homozygotes (Figure 9C). This hypertrophy/hyperplasia presumably occurred in response to the systemic insulin resistance and was responsible for hyperinsulinemia in $\mathrm{KO}$ mice.

\section{Discussion}

The present findings provide compelling evidence that aPKCs are required for insulin-stimulated glucose transport in mouse muscle. This seems clear, not only from studies of glucose transport in vivo and in vitro, but also from phenotypic abnormalities of mice with homozygous muscle-specific PKC- $\lambda$ KO. Abnormalities in glucose metabolism and expansion of islet $\beta$ cell mass and resul- 


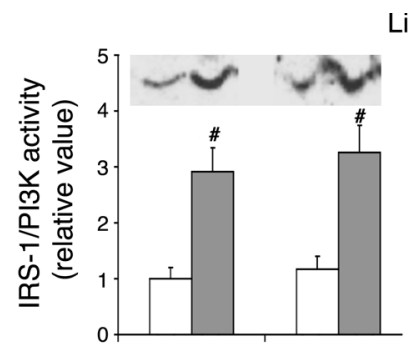

Liver
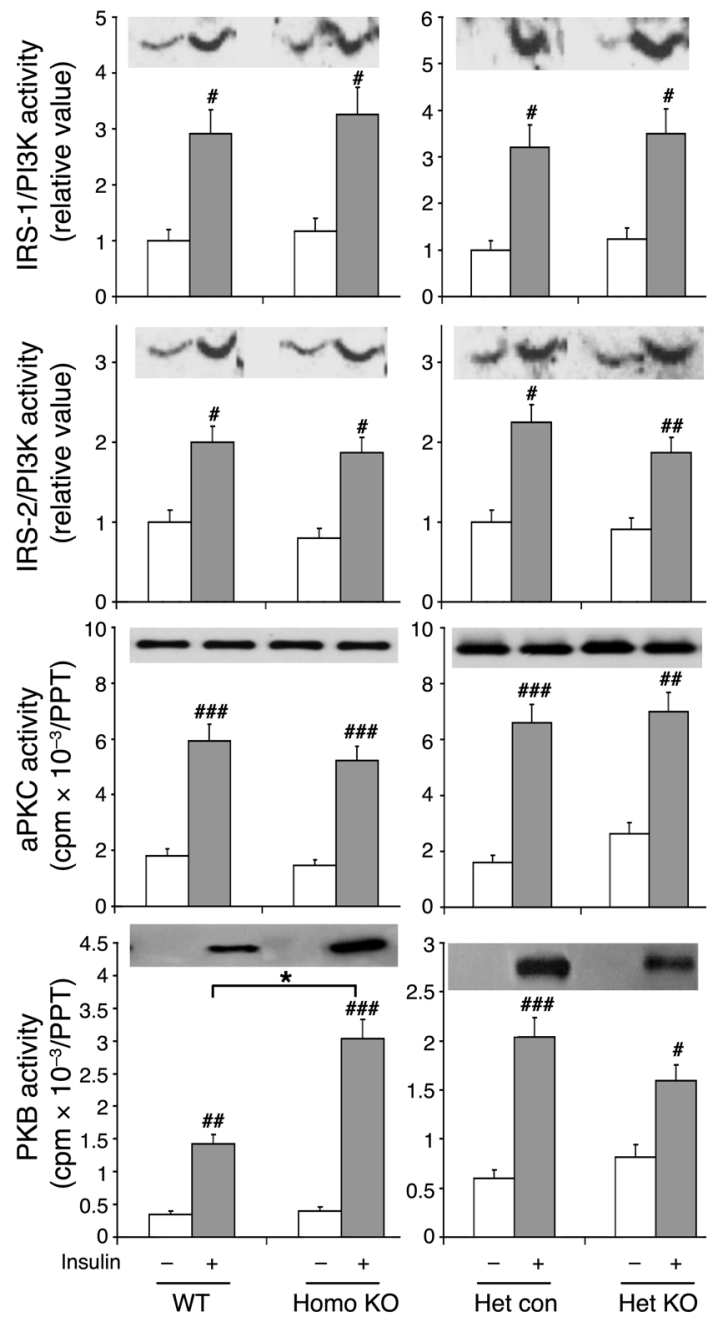

tant hyperinsulinemia in homozygotes could not be explained by impaired actions of insulin in liver and adipocytes, and therefore can reasonably be attributed to muscle aPKC deficiency.

Here, we showed a requirement for aPKC in insulin-stimulated glucose transport in mouse muscle by knocking out PKC- $\lambda$, rather than PKC- $\zeta$. We have also examined $\mathrm{PKC}-\zeta \mathrm{KO}$ mice (this $\mathrm{KO}$ is not embryonic lethal in mice), and, in contrast to the muscle-specific PKC- $\lambda$ KO mice, there was no substantial change in either total aPKC levels or insulin-stimulated glucose transport in muscle (R.V. Farese and M. Leitges, unpublished observations). Because PKC- $\lambda$ is the major aPKC in mouse muscle and PKC- $\zeta$ is a minor component (6), it is not surprising that depletion of $\mathrm{PKC}-\lambda$, but not PKC- $\zeta$, inhibited insulin-stimulated glucose transport in mouse muscle. On the other hand, PKC- $\lambda$ and $\mathrm{PKC}-\zeta$ can function interchangeably in insulin-stimulated glucose transport $(5,22)$; in addition, siRNA-mediated knockdown of PKC- $\zeta$, but not PKC- $\lambda$, inhibits insulin-stimulated glucose transport in rat-derived L6 myotubes, which are rich in PKC- $\zeta$ and have little or no PKC- $\lambda(5)$. Also note that expression of $\mathrm{PKC}-\lambda$ rescues glucose transport in L6 myotubes in which PKC- $\zeta$ is depleted; conversely, expression of $\mathrm{PKC}-\zeta$ rescues glucose transport in mouse-derived adipocytes in which PKC- $\lambda$ is depleted (5). The fact that both aPKCs can function interchangeably in glucose transport presumably reflects

\section{Figure 4}

Effects of homozygous and heterozygous muscle-specific KO of PKC- $\lambda$ on basal and insulin-stimulated activities of aPKC, PKB, IRS-1-dependent PI3K, and IRS-2-dependent PI3K in liver. Experiments were performed as described in Figure 1, A-D. Insets show representative immunoblots of hepatic aPKC and phosphorylated Ser473-PKB as well as autoradiograms of IRS-1-dependent PI3K activity with or without insulin, i.e., ${ }^{32} \mathrm{P}-\mathrm{PI}-3-\mathrm{PO}_{4}$ resolved by thin-layer chromatography. Values are mean \pm SEM. $n$ for each group is shown in parentheses. $\# P<0.05$; \#\# $P<0.01$; \#\# $P<0.001$ versus non-insulin-stimulated group of the same genotype (ANOVA). ${ }^{*} P<0.05$ (ANOVA).

evolutionary conservation of important functional domains in PKC $-\lambda$ and PKC- $\zeta$ needed for glucose transport and other essential biological functions.

Despite marked losses of PKC- $\lambda$, there were no compensatory increases in PKC- $\zeta$ levels in the muscle of $\mathrm{KO}$ mice. Also, although we were unable to measure separate enzyme activities of PKC- $\zeta$ and PKC- $\lambda$, the marked loss of total aPKC activity in muscle of $\mathrm{KO}$ mice confirmed that the activity of $\mathrm{PKC}-\zeta$ was not compensatorily increased.

The fact that PKB activation and AS160 phosphorylation were intact or enhanced in muscles of PKC- $\lambda$ KO mice is important, as it indicates that $\mathrm{aPKC}$, as well as $\mathrm{PKB}$, is required for insulinstimulated GLUT4 translocation and subsequent glucose transport. Given the complexity of the translocation process, it is not surprising that more than one insulin-sensitive protein kinase was operative in regulating this process.

It was surprising to find that phenotypic abnormalities were as prominent, or more so, in heterozygous $\mathrm{KO}$ mice than in homozygous $\mathrm{KO}$ mice. However, we found several factors that may have contributed importantly to phenotypic differences. First, insulinstimulated hepatic PKB activity, which diminishes as hyperglycemia (diabetes) ensues in rodent models (24), trended downward in heterozygotes, in contrast to the marked increases in homozygotes. Second, as in liver, insulin-stimulated PKB activation was enhanced in muscles of homozygotes, but not heterozygotes, possibly enhancing muscle glucose metabolism. Third, feeding-dependent increases in expression and nuclear levels of SREBP-1c (which transactivates multiple lipid-synthesizing enzymes, including FAS) were greater in heterozygotes and may have abetted the development of obesity and lipid abnormalities. Fourth, levels of serum FFA - which adversely alter HGP, insulin sensitivity, and glucose tolerance - were higher in heterozygotes. Fifth, correlating with abdominal obesity and hyperlipidemia, hepatosteatosis was greater in heterozygotes, and these lipid factors may diminish insulin sensitivity. Sixth, remaining PKC- $\lambda$ in heterozygote muscle was poorly responsive to $\mathrm{PIP}_{3}$, presumably impairing glucose disposal beyond that attributable to partial aPKC loss. Seventh, dietary intake was increased in heterozygotes, but not in homozygotes; further studies are needed to determine whether hypothalamic centers controlling appetite and energy consumption are altered, particularly in heterozygotes. Eighth, serum adiponectin levels were increased in homozygotes, but not in heterozygotes, and this adipokine activates 5'-AMP-dependent protein kinase and enhances insulin signaling (including PKB activation/phosphorylation) and actions in muscle and liver (25). However, whether adiponectin favorably influenced muscle and liver PKB activation and hepatic SREBP-1c expression in homozygotes, and why adiponectin secretion was increased in homozygotes but not in heterozygotes, are unclear. 
A

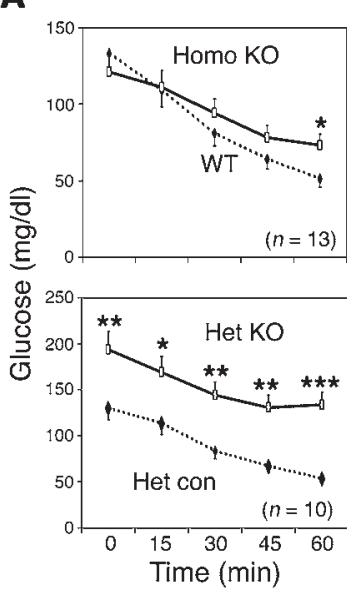

B

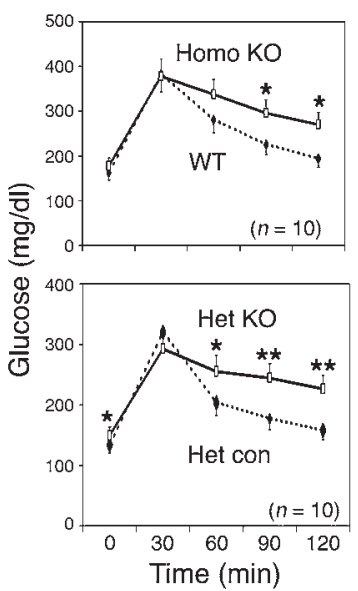

Male

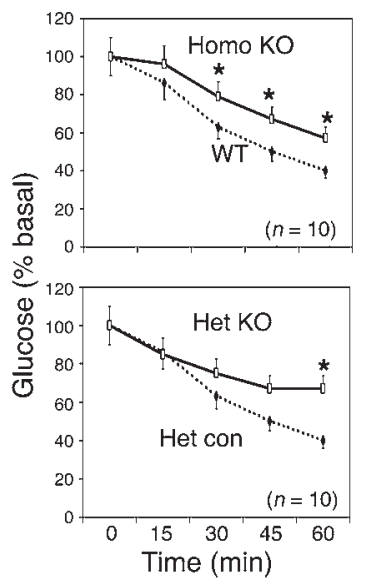

Male

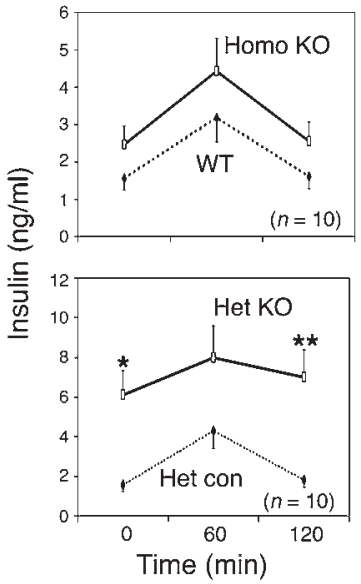

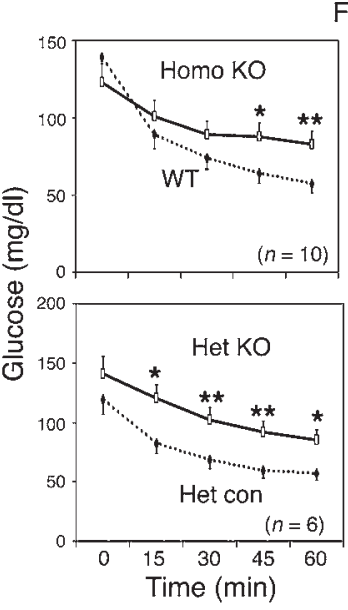

Female

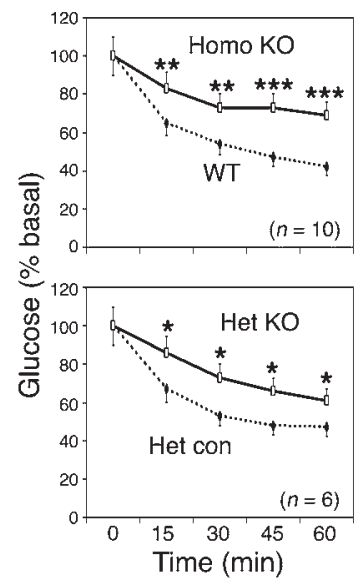

Female
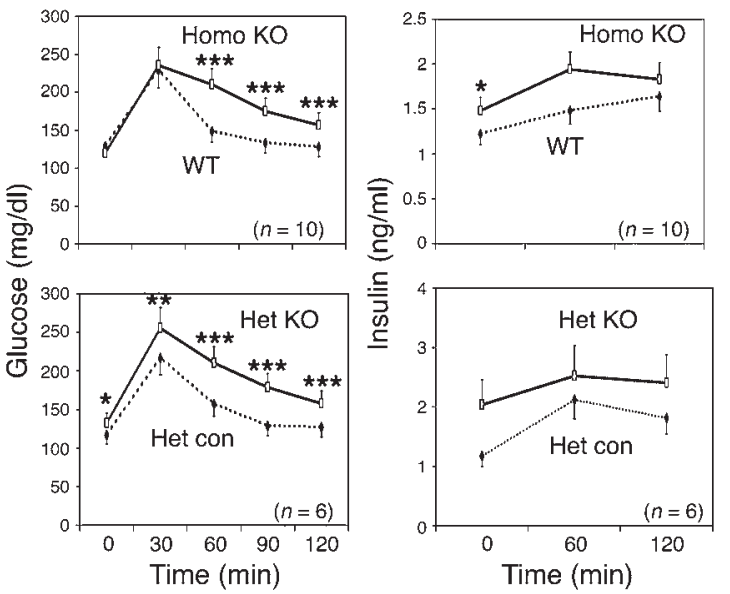

Figure 5

Effects of homozygous and heterozygous muscle-specific KO of PKC- $\lambda$ on insulin tolerance (A) and glucose tolerance (B) in 5-month-old male and female mice fasted for 4-6 hours. (A) Insulin tolerance was determined by i.p. administration of $0.75 \mathrm{mU}$ insulin per gram body weight. (B) Glucose tolerance was determined by i.p. administration of $2 \mathrm{mg}$ glucose per gram body weight. Values of tail vein blood glucose and serum insulin are mean \pm SEM. $n$ for each group is shown in parentheses. ${ }^{*} P<0.05$; ${ }^{* \star} P<0.01$; ${ }^{* *} P<0.001$ versus respective control (ANOVA).

In considering factors that influence phenotypes, hepatosteatosis and abdominal obesity as well as elevated serum FFA/triglyceride levels may have intensified insulin resistance and insulinmediated phenotypic abnormalities. Indeed, a vicious cycle may exist in which alterations in lipid metabolism increase insulin resistance and, conversely, insulin resistance and resulting hyperinsulinemia increase obesity and serum lipid abnormalities, particularly in heterozygotes.

The reason for excessive increases in insulin-stimulated PKB activation and phosphorylation in liver and muscle of homozygotes is uncertain, but did not appear to reflect alterations in PKB levels or activation of signaling factors immediately upstream of PKB, namely IRS-1-dependent PI3K in muscle $(26,27)$ and both IRS-1-dependent and IRS-2-dependent PI3K in liver (26-28). In support of this idea, activation of hepatic aPKC, which, like PKB, is dependent on IRS-2-dependent PI3K $(27,28)$ and 3-phosphoinositide-dependent protein kinase 1 (PDK1), was not excessive in homozygous liver. On the other hand, Ser473-PKB phosphorylation was increased in liver and muscle, and factors that phosphorylate Ser473 include not only a putative PDK2 (29), but also other kinases such as MAPK2, p38 MAPK, mTOR, PKC- $\alpha$, and PKC- $\beta$; unfortunately, the significance of these kinases is poorly understood (30). Interestingly, Ser473-PKB phosphorylation is improved in insulin-resistant mice by adiponectin (25), which was increased in homozygotes, but not in heterozygotes (the latter failure may reflect greater adiposity, which correlates inversely with adiponectin). The lack of increase in serum adiponectin and PKB activity and phosphorylation in liver and muscle may be particularly important for the greater-than-expected phenotypic abnormalities we observed in heterozygotes. Further studies are needed to examine these and other reasons for phenotypic differences.

Findings in $\mathrm{KO}$ mice, particularly homozygotes, may be relevant to the question of whether features of the metabolic syndrome, most notably hyperlipidemia and obesity, reflect excessive or diminished insulin effects in liver and/or adipocytes. In homozygotes, insulin-stimulated glucose transport in adipocytes was intact and fat stores were increased; moreover, insulin signaling in liver was normal or enhanced, and HGP was not significantly altered. Thus, at least in homozygotes, alterations in serum triglycerides, FFAs, and LDL-cholesterol and HDL-cholesterol occurred in the 

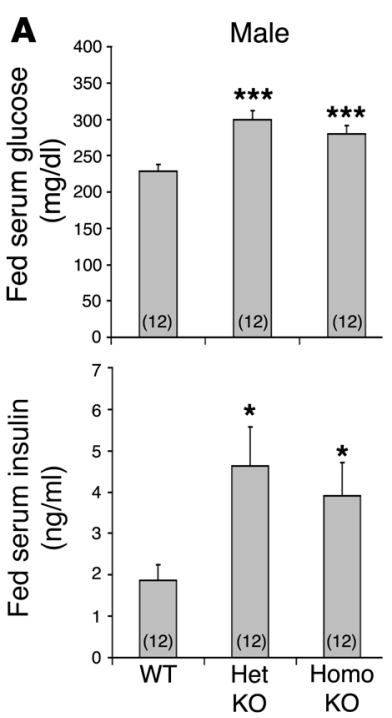
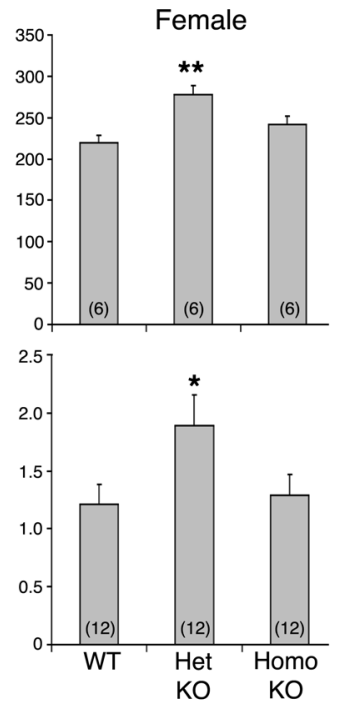

B

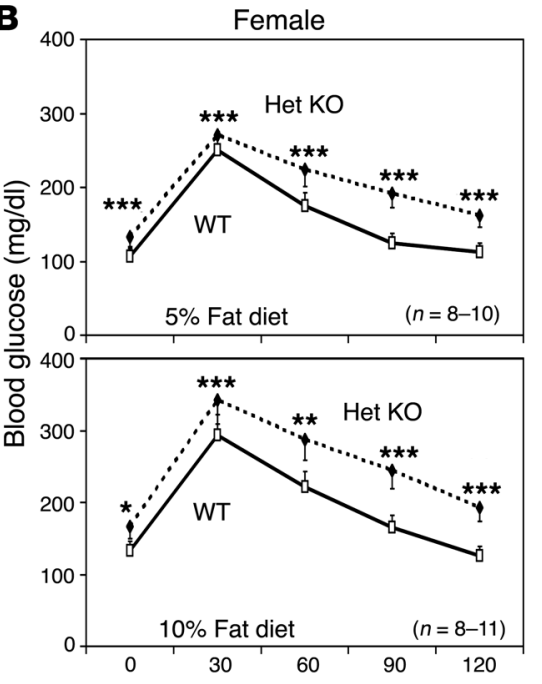

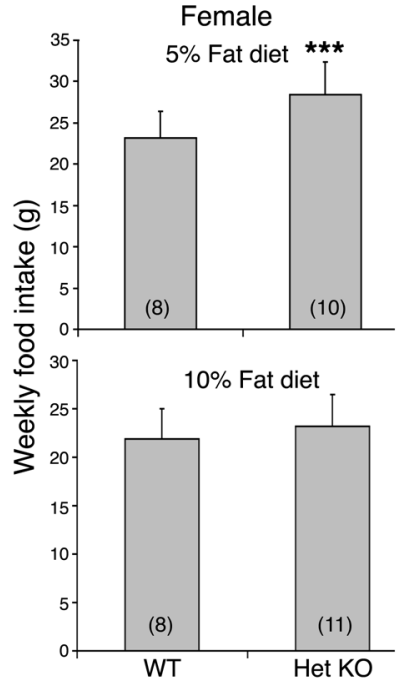

Figure 6

Alteration in serum glucose and insulin levels and food intake in KO mice. (A) Serum glucose and insulin levels in ad libitum standard chow-fed 5-month-old male and female WT, heterozygous KO, and homozygous KO mice. (B) Glucose tolerance tests (see Figure 5) and dietary intake in 7-month-old female heterozygous KO and WT mice that were followed for 2 months while being fed standard chow or chow with increased dietary fat $\left(5 \%\right.$ or $10 \%$ fat by weight, respectively). Values are mean \pm SEM. $n$ for each group is shown in parentheses. ${ }^{\star} P<0.05 ;{ }^{* \star} P<0.01$; ${ }^{* *} P<0.001$ versus WT (ANOVA).

absence of measurable defects in insulin signaling or action in adipocytes and liver. We therefore surmise that in homozygotes, (a) metabolic syndrome features including abdominal obesity and hyperlipidemia reflected enhanced, rather than diminished, insulin actions in liver and adipocytes, and (b) hyperinsulinemia caused by impaired muscle glucose transport is sufficient to cause or abet the development of abdominal obesity and hyperlipidemia.

It is interesting to compare the phenotype of mice with musclespecific $\mathrm{KO}$ of $\mathrm{PKC}-\lambda$ to that of mice with muscle-specific $\mathrm{KO}$ of Glut 4 or insulin receptor. As with PKC- $\lambda \mathrm{KO}$, muscle-specific Glut4 KO mice display similar loss of insulin-stimulated glucose transport with associated insulin resistance and glucose intolerance; however, unlike PKC- $\lambda \mathrm{KO}$, insulin action is defective in adipocytes and liver, hyperglycemia is more prominent, and obesity and hyperlipidemia are absent in muscle-specific Glut $4 \mathrm{KO}$ mice (31-33). On the other hand, mice with muscle-specific insulin receptor $\mathrm{KO}$ are obese and have elevated serum triglycerides and FFAs as did PKC- $\lambda$ KO mice; however, unlike PKC- $\lambda$ KO, these mice do not display hyperinsulinemia or glucose intolerance, at least initially, perhaps reflecting increases in adipose-dependent glucose disposal $(33,34)$.

It is also interesting to compare phenotypes of $\mathrm{KO}$ mice with muscle-specific PKC- $\lambda$ deficiency versus those of mice with partial (heterozygous) deficiency of total-body Glut4 (35). Like heterozygous and homozygous $\mathrm{PKC}-\lambda \mathrm{KO}$ mice, heterozygous Glut4 KO mice have severe skeletal muscle insulin resistance and hyperinsulinemia, but, unlike $\mathrm{PKC}-\lambda \mathrm{KO}$ mice, obesity is not evident, FFA levels are normal, and fasting plasma glucose levels are initially normal $(35,36)$. Apparently, intact liver responsiveness can effectively counteract peripheral insulin resistance in heterozygous Glut4 KO mice (35).

Another interesting comparison is with mice with combined $\mathrm{KO}$ of Glut4 in muscle and adipocytes. These mice, like muscle-specific
PKC- $\lambda$ KO mice, are insulin resistant and glucose intolerant or diabetic, but are not obese and do not have elevated serum triglyceride or FFA levels, perhaps reflecting diminished adipogenesis and enhanced clearance and utilization of liver-derived lipids by muscle (37).

From these comparisons, the muscle-specific PKC- $\lambda$ KO mouse model appears to be unique in mimicking - within the same mouse - most, if not all, metabolic syndrome features seen in humans. Moreover, blood glucose levels apparently can progress to at least mild diabetic levels with age and increased dietary fat and/or caloric content in this model.

Finally, it is important to consider findings in muscle-specific PKC- $\lambda$ KO mice in the context of human obesity, IGT, and T2DM. First, glucose-tolerant first-degree relatives of humans with T2DM have defects in glucose disposal and muscle glucose transport, despite normal PKB activation and action (38); it will be interesting to examine aPKC levels and activation in these muscles. Second, insulin-stimulated glucose transport and aPKC activation are defective in cultured myocytes of obese IGT subjects (19); why these defects persist in passaged myocytes is intriguing. Third, humans with IGT and T2DM have 35\%-40\% lower aPKC levels and even more severe defects in aPKC activation in muscle $(17,20$, $21)$, similar to what we observed in heterozygous PKC- $\lambda$ KO mice. Accordingly, alterations in insulin sensitivity, glucose metabolism, serum lipids, and adiposity in human forms of IGT and T2DM may, at least in part, reflect the known abnormalities in muscle aPKC in these conditions in humans. On the other hand, nonaPKC insulin signaling defects have also been found in human T2DM muscle, including defective activation of IRS-1-dependent PI3K (39) and PKB (40-42), and these abnormalities undoubtedly contribute importantly to the phenotype of patients with T2DM.

In summary, our findings show that defects in aPKC availability and/or activation limited glucose transport in muscles of intact mice. Moreover, this tissue-specific limitation in transport was 


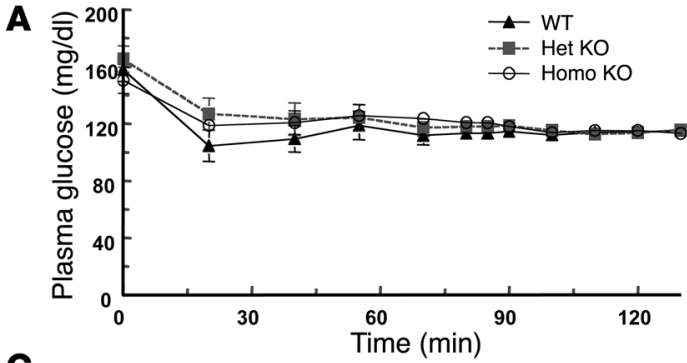

C
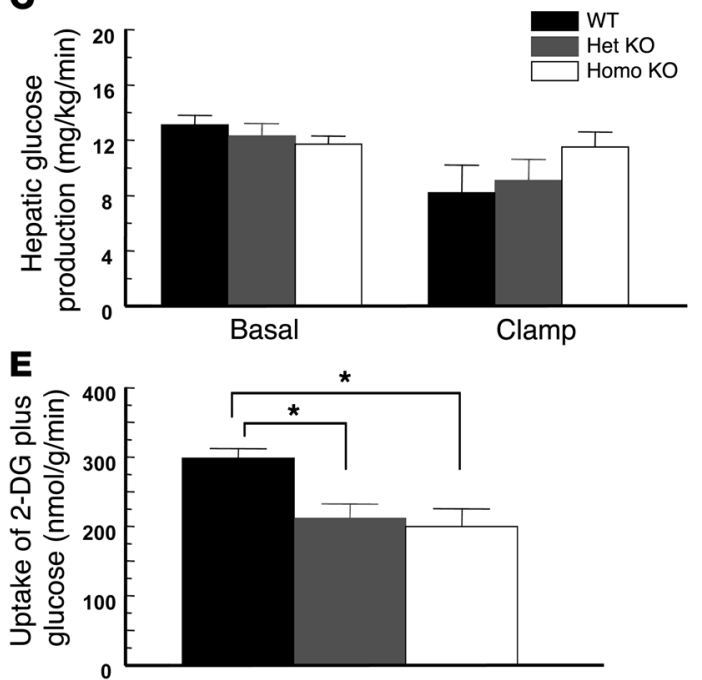

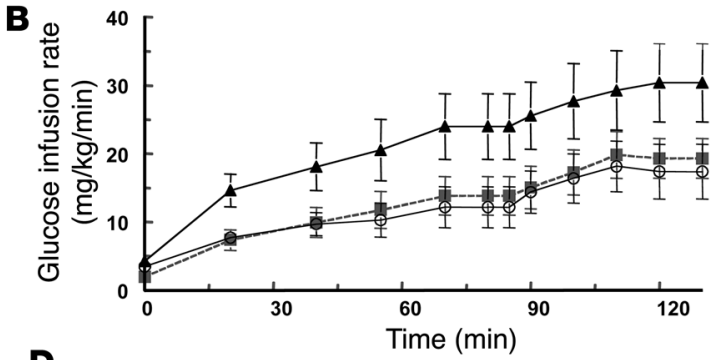

D

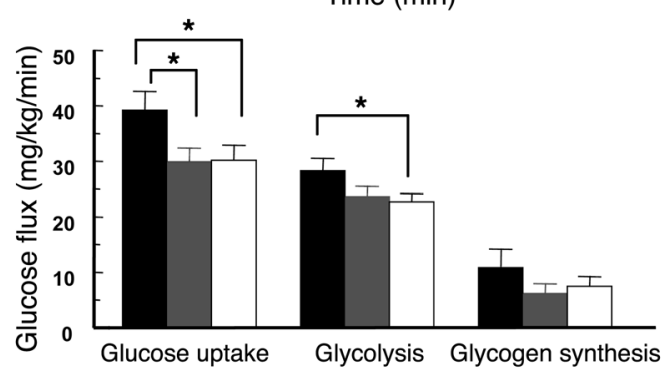

Figure 7

Effects of muscle-specific heterozygous and homozygous musclespecific KO of PKC- $\lambda$ on peripheral glucose disposal and HGP during hyperinsulinemic-euglycemic clamps. (A) Plasma glucose. (B) Glucose infusion rates. (C) HGP. (D) Whole-body glucose uptake, glycolysis, and glycogen synthesis. (E) Skeletal muscle (gastrocnemius) glucose uptake. Data are mean \pm SEM for $10-11$ mice per group. ${ }^{*} P<0.05$. accompanied by an insulin-resistant, glucose-intolerant, hyperlipidemic, abdominal obesity-prone, hepatosteatotic phenotype. Although the relevance of muscle-specific aPKC deficiency in mice to obesity, the metabolic syndrome, and T2DM in humans requires further scrutiny, the presently described mouse heterozygous and homozygous muscle-specific PKC- $\lambda$ KO models seem well suited to provide readily available and effective means for devising and testing new therapies for these global health problems.

\section{Methods}

Muscle-specific KO of PKC- $\lambda$. We have previously reported on introduction of loxP sites flanking the exon at nucleotides $110-233$ in genomic mouse PKC- $\lambda$, insertion of floxed PKC- $\lambda$ into mouse ES cells, and deletion of floxed PKC- $\lambda$ by expression of Cre recombinase in ES cells (22). ES cells containing the floxed PKC- $\lambda$ allele were used to generate mice (C57BL/6 and $129 \mathrm{P} 2 /$ Sv background) with germline-transmitted floxed PKC- $\lambda$, and these mice were crossed with mice (FVB background) harboring an MCKregulated Cre recombinase transgene to generate heterozygous and homozygous muscle-specific PKC- $\lambda$ KO mice and various littermates.

Mouse care. Mice were maintained in light- and temperature-controlled environments (12-hour light/12-hour dark, $20-24^{\circ} \mathrm{C}$ ) in Vivaria of the James A. Haley Veterans Administration Hospital and Yale University School of Medicine. Mice were fed standard chow containing 5\% fat by weight, and some mice were fed a $10 \%$ fat diet for 2 months. Protocols were approved by the Institutional Animal Care Committees of the University of South Florida College of Medicine or of the Yale University School of Medicine. Studies were in accordance with guidelines of the National Institutes of Health and Principles of the Declaration of Helsinki.

Genotyping. DNA was isolated from tail clips with a DNAeasy Kit (QIAGEN). For detection of the MCK-controlled Cre recombinase transgene, PCR was performed with JumpStart ReadyMix REDTaq DNA polymerase (Sigma-Aldrich) using primers ATGTCCAATTTACTGACCG (forward) and CGCGCCTGAAGATATAGAAG (reverse). For detection of the loxP site, the primers were TTGTGAAAGCGACTGGATTG (forward) and CTTGGGTGGAGAGGCTATTC (reverse). For detection of WT, primers were TTGTGAAAGCGACTGGATTG (forward) and AATGTTCATGTTCAACACTGCT (reverse). For detection of the deletion, primers were ACTAGCATTGCCTGGCATC (forward) and AATGTTCATGTTCAACACTGCT (reverse).

Glucose transport in vivo. As described previously $(23,43)$, following a 16- to 20 -hour overnight fast, $0.2 \mathrm{ml}$ physiologic saline containing the following was administered i.p. 10 minutes before killing: $0.05 \mu \mathrm{Ci}\left[{ }^{3} \mathrm{H}\right] 2-\mathrm{DG}$ per gram body weight (NEN/Life Science Products Inc.); $0.005 \mu \mathrm{Ci}$ $\left[{ }^{14} \mathrm{C}\right] \mathrm{L}$-glucose (NEN/Life Science Products Inc.); and where indicated, $1 \mathrm{mU}$ insulin (Sigma-Aldrich), a dosage just sufficient to elicit maximal increases in insulin signaling to PKB and aPKC in muscle and liver. Glucose uptake in muscle was measured by dividing the tissue $\left[{ }^{3} \mathrm{H}\right]$-cpm (corrected for nonspecific trapping of extracellular water per $\left[{ }^{14} \mathrm{C}\right] \mathrm{L}$-glucose radioactivity) by the specific ${ }^{3} \mathrm{H}$-radioactivity of serum 2-DG/glucose.

GLUT4 translocation in vivo. Mice fasted overnight were treated for $20 \mathrm{~min}-$ utes with $1 \mathrm{mU}$ insulin per gram body weight; vastus lateralis and gastrocnemius muscles were harvested, homogenized, and subjected to ultracentrifugation to purify plasma and internal membranes in a discontinuous sucrose gradient; and Glut4 was measured by Western blot analysis (4-6). Plasma membrane recovery was monitored by Western blot analysis of $\beta$ subunits of insulin and IGF-1 receptors.

Glucose transport in isolated muscles. Extensor digitorum longus and soleus muscles were obtained from male mice, stretched to maintain resting length and tension, and incubated under $95 \% \mathrm{O}_{2} / 5 \% \mathrm{CO}_{2}$ in glucose-free Krebs-Ringer bicarbonate medium containing $1 \mathrm{mM}$ sodium pyruvate 
A
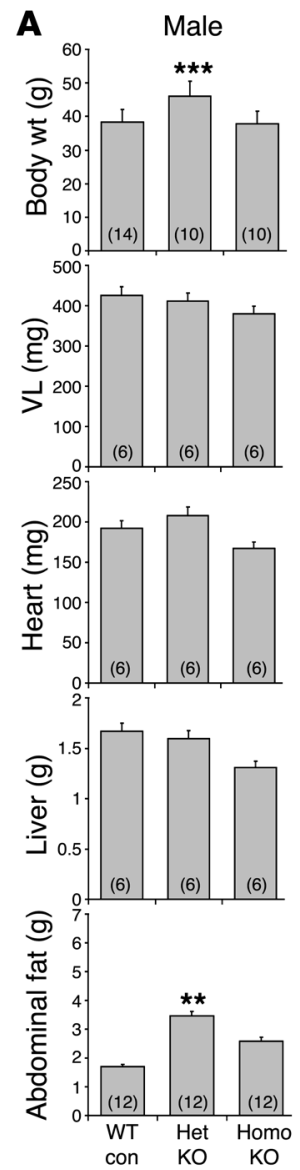

Female
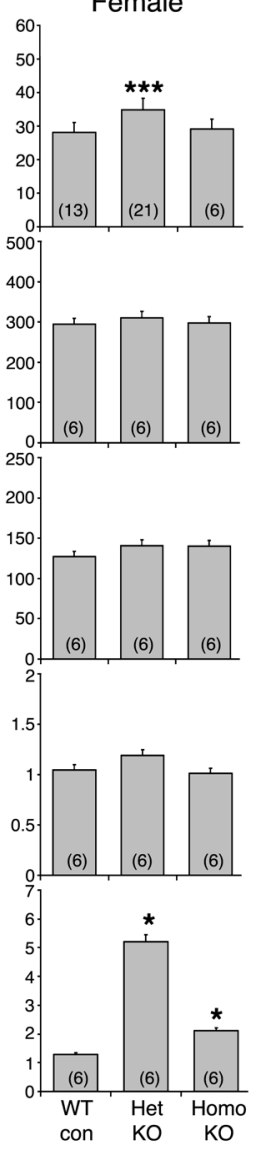
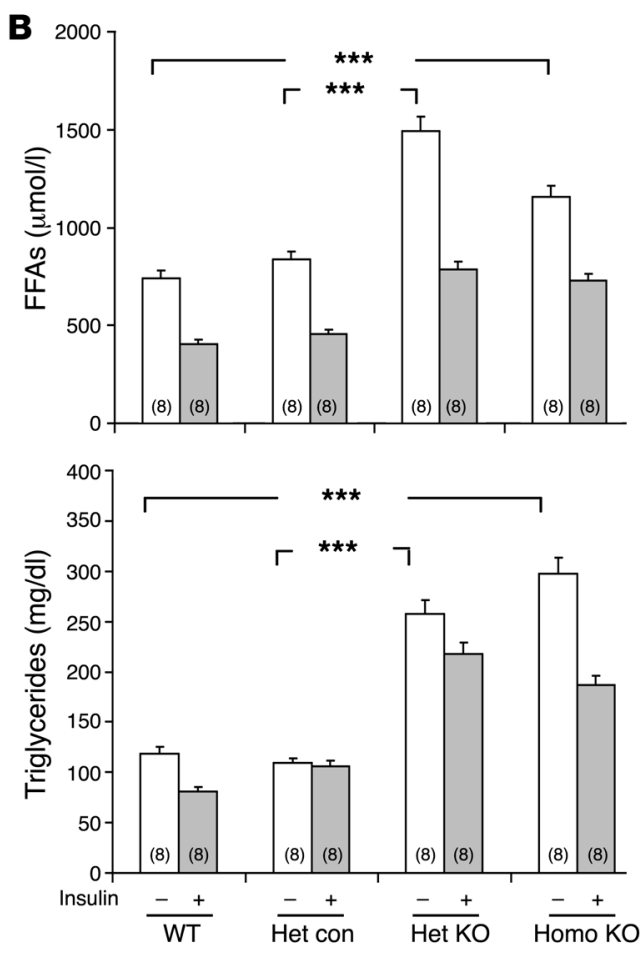

C

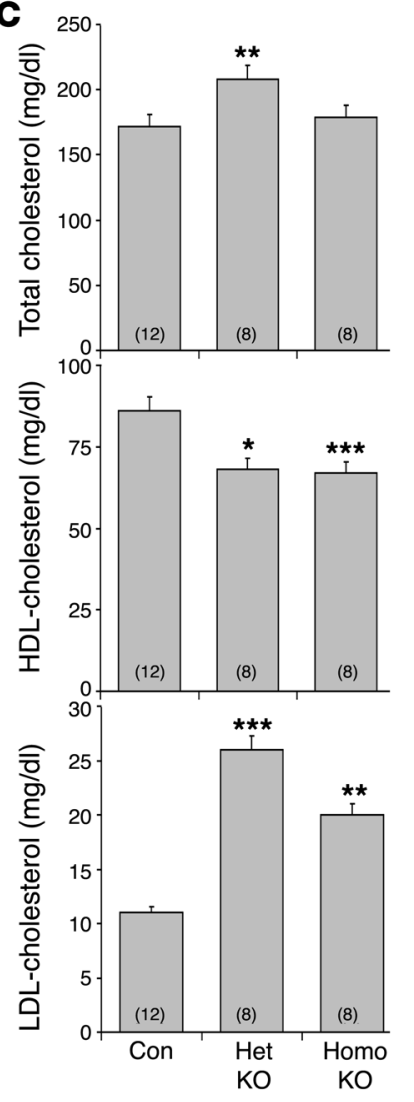

Figure 8

Effects of homozygous and heterozygous muscle-specific KO of PKC- $\lambda$ on (A) total body weight and weight of abdominal fat, vastus lateralis muscle, heart ventricle muscle, and liver; (B) serum levels of FFAs and triglycerides; and (C) serum levels of total cholesterol, LDL-cholesterol, and HDL-cholesterol in 5-month-old mice. (A and C) The control group included pooled results of true WT and heterozygous control mice, which were indistinguishable. Ad libitum-fed mice were used in A. (B and C) Equal numbers of 20-hour-fasted male and female mice were used; results were indistinguishable and therefore pooled. (B) Mice were injected i.p. with saline or insulin (1 U/kg body wt) 10 minutes before killing. Values are mean \pm SEM. $n$ for each group is shown in parentheses. ${ }^{*} P<0.05 ;{ }^{* \star} P<0.01$; ${ }^{* \star *} P<0.001$ versus WT or as indicated by brackets (ANOVA).

as an energy source, first for 30 minutes with or without $100 \mathrm{nM}$ insulin, and then for 5 minutes with $50 \mu \mathrm{M}\left[{ }^{3} \mathrm{H}\right] 2-\mathrm{DG}$ and trace amounts of $\left[{ }^{14} \mathrm{C}\right] \mathrm{L}$-glucose to correct for nonspecific trapping of extracellular water, as described previously $(23,43)$.

Glucose transport in adipocytes. As described previously (43), pooled epididymal and intra-abdominal adipose tissues were digested with collagenase and isolated adipocytes (6\% adipocrit) were incubated first for 30 minutes in glucose-free Krebs-Ringer phosphate medium without or with insulin and then for 1 minute with $50 \mu \mathrm{M}\left[{ }^{3} \mathrm{H}\right] 2-\mathrm{DG}$, after which uptake of label was measured by flotation of adipocytes through oil.

aPKC activation. aPKC activity was measured as described previously $(1,2,4-6,18,20,23,24,44)$. Briefly, aPKCs were immunoprecipitated with a rabbit polyclonal antiserum (Santa Cruz Biotechnology Inc.) that recognizes the $\mathrm{C}$ termini of PKC- $\lambda$ and PKC- $\zeta$; collected on Sepharose-AG beads; and incubated for 8 minutes at $30^{\circ} \mathrm{C}$ in $100 \mu \mathrm{l}$ buffer containing $50 \mathrm{mmol} / \mathrm{l}$ Tris- $\mathrm{HCl}(\mathrm{pH} 7.5), 100 \mu \mathrm{mol} / 1 \mathrm{Na}_{3} \mathrm{VO}_{4}, 100 \mu \mathrm{mol} / 1 \mathrm{Na}_{4} \mathrm{P}_{2} \mathrm{O}_{7}$, $1 \mathrm{mmol} / \mathrm{l} \mathrm{NaF}, 100 \mu \mathrm{mol} / \mathrm{l} \mathrm{PMSF}, 4 \mu \mathrm{g}$ phosphatidylserine (Sigma-Aldrich), $50 \mu \mathrm{mol} / 1\left[\gamma_{-}{ }^{32} \mathrm{P}\right]$ ATP (NEN/Life Science Products Inc.), $5 \mathrm{mmol} / 1 \mathrm{MgCl}_{2}$, and, as substrate, $40 \mu \mathrm{mol} / 1$ serine analog of the PKC- $\varepsilon$ pseudosubstrate (BioSource). After incubation, ${ }^{32} \mathrm{P}-$-labeled substrate was trapped on P-81 filter paper and counted in a liquid scintillation counter.
PKB/Akt activation. PKB activation was assessed as described previously $(4-6,18,20,24,44)$ by Western blot analysis and immunoblotting for PDK2dependent phosphorylation of Ser473 in PKB, enzymatic activity of immunoprecipitable PKB using antibodies and assay reagents supplied by Upstate, and phosphorylation of PKB substrates GSK3 $\alpha$, GSK3 $\beta$, and AS160.

IRS-1-dependent and IRS-2-dependent PI3K activation. IRS-1-dependent and IRS-2-dependent PI3K activities were measured as previously described $(4-6,18,20,24,44)$. Briefly, IRS-1 or IRS-2 was precipitated with rabbit polyclonal antiserum (Upstate) and incubated with phosphatidylinositol substrate to generate ${ }^{32} \mathrm{P}-\mathrm{PI}-3-\mathrm{PO}_{4}$, which was purified by thin-layer chromatography and quantified in a Bio-Rad Phosphorimager.

Western blot analyses. As described (4-6, 18, 20, 23, 24, 44), muscle lysates were immunoblotted for PKC- $\zeta / \lambda$ (rabbit polyclonal antiserum; Santa Cruz Biotechnology Inc.), which recognizes C-termini of both aPKCs; phosphorylated Ser473-PKB (rabbit polyclonal antiserum; Upstate); IRS-1 (rabbit polyclonal antiserum; Upstate); phosphorylated AS160 (rabbit polyclonal antiserum; Cell Signaling Technology Inc.); mouse monoclonal anti-GLUT4 antibody (AbD Serotec Ltd.); rabbit polyclonal anti-GLUT1 antiserum (Santa Cruz Biotechnology Inc.); rabbit polyclonal anti-PKC- $\lambda$ and anti-PKC- $\zeta$ antisera (prepared by M. Leitges); goat polyclonal antiPKB- $\alpha / \beta$ antisera (Santa Cruz Biotechnology Inc.); rabbit polyclonal 

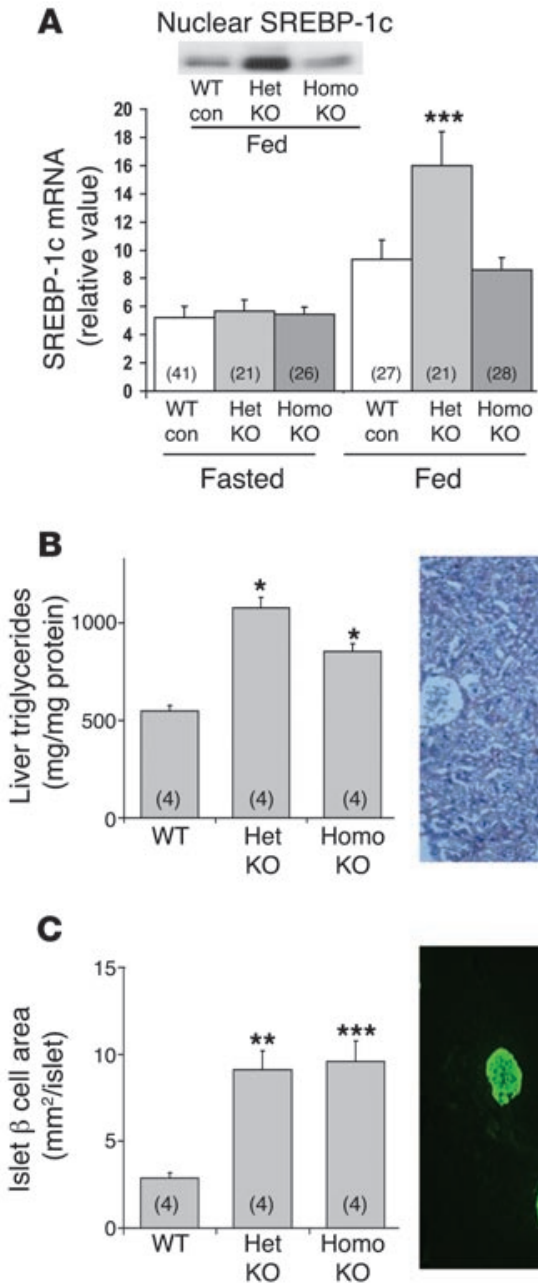

\section{Figure 9}

Effects of homozygous and heterozygous muscle-specific KO of PKC- $\lambda$ on hepatic SREBP-1c and FAS expression, liver lipids, and islet $\beta$ cell volume. (A) Expression of hepatic SREBP-1c and FAS by quantitative real-time RT-PCR in overnight fasted and ad libitum-fed conditions. Inset shows active nuclear SREBP-1c immunoreactivity. The control group included pooled results of true WT and heterozygous control male mice, which were comparable. (B) Livers of 5-month-old fed male WT and KO mice were examined by Oil Red O staining of lipids in frozen liver sections and chemical analysis of triglyceride levels in liver homogenates. (C) Livers of mice as in $\mathbf{B}$ were examined by islet anti-insulin immunohistological analysis of $\beta$ cell volume, and representative insulin-stained areas are shown. After immunologic development of insulin-stained cells, mean cross-sectional areas of $\beta$ cell regions of islets were determined from 6 random microscopic areas (each containing 2-5 islets) from each of 4 mice per group. Original magnification, $\times 10$. Values are mean \pm SEM. $n$ for each group is shown in parentheses. ${ }^{\star} P<0.05 ;{ }^{* \star} P<0.01 ;{ }^{* \star} P<0.001$ versus WT (ANOVA).

anti-PKB- $\alpha / \beta$ antiserum (Upstate); rabbit polyclonal anti-GSK3 $\alpha$ and anti-GSK3 $\beta$ antisera (Cell Signaling Technology); mouse monoclonal anti-SREBP-1c antibody (Neomarkers Inc.); and rabbit polyclonal antiinsulin receptor $\beta$ subunit and anti-IGF-1 receptor $\beta$ subunit antisera (Santa Cruz Biotechnology Inc.).

Nuclear preparation. Liver nuclei were prepared with NE-PER Nuclear and Cytoplasmic Extraction Reagents obtained from Pierce Biotechnology.

$m R N A$ analyses. Tissues were added to TRIzol reagent (Invitrogen), and RNA was extracted and purified with an RNA-Easy Mini-Kit and RNAasefree DNAase kit (QIAGEN), quantified by measuring $A_{260} / A_{280}$, and checked for purity by electrophoresis on $1.2 \%$ agarose gels; mRNA was quantified by quantitative real-time RT-PCR. Reverse transcription was accomplished with TaqMan reverse transcription reagent from Applied Biosystems. Mouse
SREBP-1c mRNA was measured with a SYBR Green kit (Applied Biosystems) using primers at nucleotides ATCGGCGCGGAAGCTGTCGGGGTAGCGTC (forward) and ACTGTCTTGGTTGATGAGCTGGAGCAT (reverse). Mouse FAS was measured with primers GAGGACACTCAAGTGGCTGA (forward) and GTGAGGTTGCTGTCGTCTGT (reverse). The housekeeping gene hypoxanthine phosphoribosyl-transferase, used for recovery correction, was measured with primers TGAAAGACTTGCTCGAGATGTCA (forward) and AAAGAACTTATAGCCC CC CTTGA (reverse).

Blood, serum, and tissue analyses. Serum glucose was measured using a OneTouch SureStep glucometer from LifeScan (Johnson \& Johnson). Immunoreactive insulin was measured using a sensitive insulin RIA kit (catalog SRI-13K) from Linco Inc. Nonesterified FFAs were measured by NEFA C (cata$\log$ 994-75409) from Wako. Serum triglycerides were measured using the Serum Triglycerides Determination kit (catalog TR0100) from Sigma-Aldrich. Total cholesterol, LDL-cholesterol, and HDL-cholesterol were measured by an Advia 1650 Autoanalyzer (Bayer Instruments). Adiponectin, leptin, and resistin were measured by Quantikine kits (R\&D Systems).

Hyperinsulinemic-englycemic clamps. Mice used in clamp studies were allowed free access to water and food following transfer to the Yale University School of Medicine. Seven days prior to the hyperinsulinemic euglycemic clamp studies, indwelling catheters were placed into the right internal jugular vein extending to the right atrium. After overnight fast, $\left[3-{ }^{3} \mathrm{H}\right]$ glucose (HPLC purified; Perkin Elmer Inc.) was infused at a rate of $0.05 \mu \mathrm{Ci} / \mathrm{min}$ for 2 hours to assess the basal glucose turnover. Following the basal period, hyperinsulinemic euglycemic clamps were conducted for 130 minutes with a primed/continuous infusion of human insulin (126 pmol/kg prime, $18 \mathrm{pmol} / \mathrm{kg} / \mathrm{min}$ infusion; Novo Nordisk Co.) to raise plasma insulin to within the physiological range. Blood samples $(10 \mu \mathrm{l})$ were collected at 10 - to 20 -minute intervals for the immediate measurement of plasma glucose, and $20 \%$ dextrose was 
A
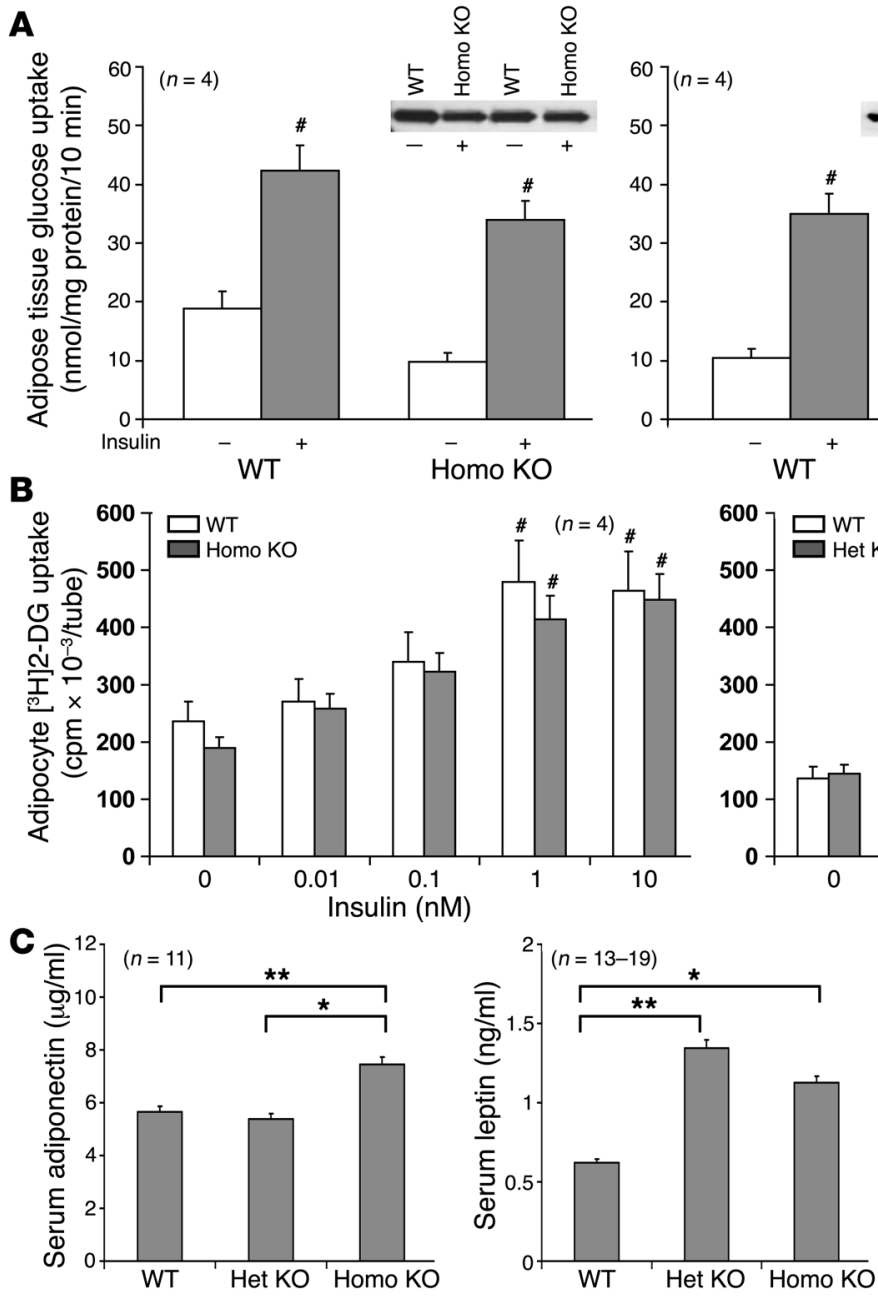
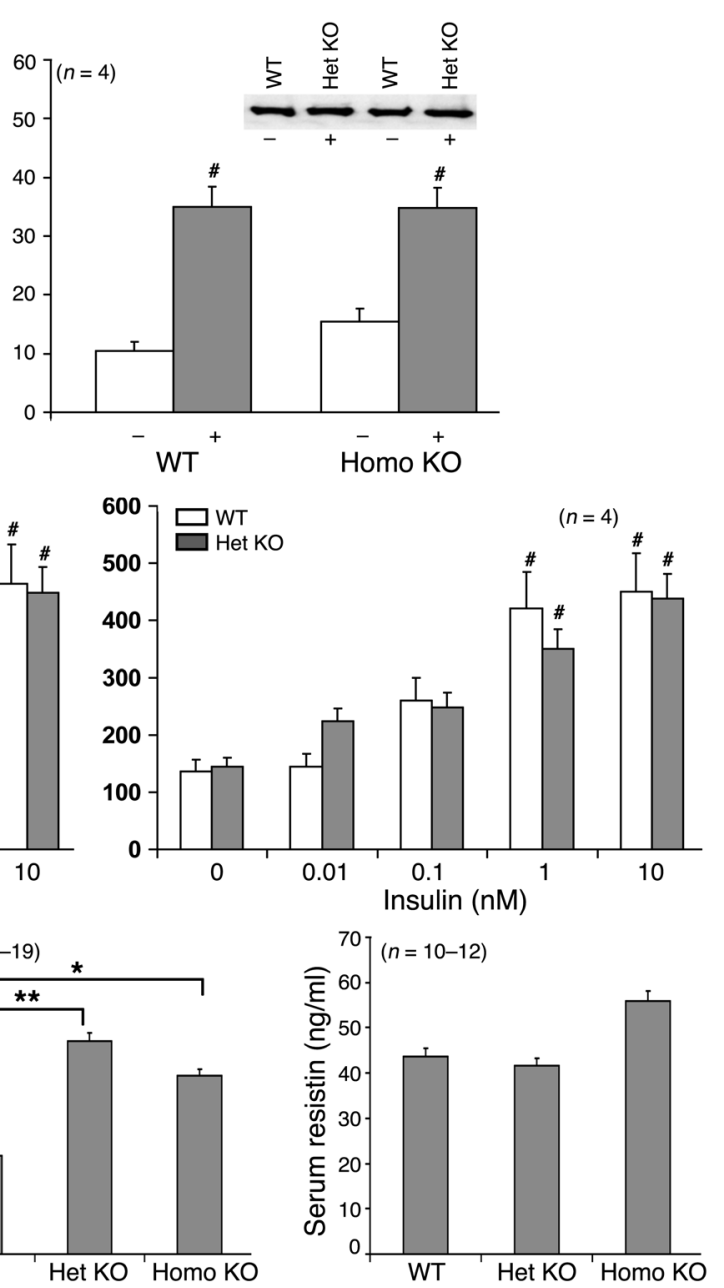

Figure 10

Effects of homozygous and heterozygous muscle-specific $\mathrm{KO}$ of PKC- $\lambda$ on basal and insulin-stimulated glucose uptake and transport in whole adipose tissue, isolated adipocytes, and serum adipokines. (A) Glucose transport was measured in adipose tissues obtained from WT, homozygous $\mathrm{KO}$, and heterozygous $\mathrm{KO}$ mice treated with or without insulin in vivo, as described in Figure 1. Insets show aPKC levels in indicated groups with or without insulin. (B) Adipocytes isolated from male mice were incubated with increasing concentrations of insulin. (C) Results in ad libitum-fed male mice. Values are mean \pm SEM. $n$ for each group is shown in parentheses. ${ }^{\#} P<0.05$ versus non-insulinstimulated group of the same genotype (ANOVA). ${ }^{*} P<0.05$; ${ }^{\star \star} P<0.01$ (ANOVA). infused at variable rates to maintain plasma glucose at basal concentrations $(\sim 6.7 \mathrm{mM})$. To estimate insulin-stimulated whole-body glucose fluxes, $\left[3{ }^{3} \mathrm{H}\right]$ glucose was infused at a rate of $0.1 \mu \mathrm{Ci} / \mathrm{min}$ throughout the clamps, and 2-deoxy-D-[1- $\left.{ }^{14} \mathrm{C}\right]$ glucose $\left(2-\left[{ }^{14} \mathrm{C}\right] \mathrm{DG}, \mathrm{HPLC}\right.$ purified; PerkinElmer) was injected as a bolus 75 minutes into the clamp to estimate the rate of insulin-stimulated tissue glucose uptake, as described previously (45). Blood samples $(10 \mu \mathrm{l})$ for the measurement of plasma $\left[{ }^{3} \mathrm{H}\right]$ glucose and $\left[{ }^{14} \mathrm{C}\right]$ glucose activities were taken at the end of the basal period and during the last 45 minutes of the clamp. Additional blood samples were obtained for the measurement of plasma insulin and FFA concentrations at the end of basal and clamp periods. At the end of the clamp, mice were anesthetized with pentobarbital sodium injection, and tissues were taken for biochemical measurements within 4 minutes. Each tissue, once exposed, was dissected out within 2 seconds, frozen immediately using liquid $\mathrm{N}_{2}$-cooled aluminum blocks, and stored at $-80^{\circ} \mathrm{C}$ for subsequent analysis.

Glucose flux calculation. For the determination of plasma ${ }^{3} \mathrm{H}$-glucose, plasma was deproteinized with $\mathrm{ZnSO}_{4}$ and $\mathrm{Ba}(\mathrm{OH})_{2}$, dried to remove ${ }^{3} \mathrm{H}_{2} \mathrm{O}$, resuspended in water, and counted in scintillation fluid (Ultima Gold; PerkinElmer) in a Beckman Coulter scintillation counter. Rates of basal and insulin-stimulated whole-body glucose turnover were determined as the ratio of the $\left[3-{ }^{3} \mathrm{H}\right]$ glucose infusion rate $(\mathrm{dpm} / \mathrm{min})$ to the specific activity of plasma glucose $(\mathrm{dpm} / \mu \mathrm{mol})$ at the end of the basal period and during the final 30 minutes of the clamp experiment, respectively. HGP was determined by subtracting the glucose infusion rate from the total glucose appearance rate.

The plasma concentration of ${ }^{3} \mathrm{H}_{2} \mathrm{O}$ was determined by the difference between ${ }^{3} \mathrm{H}$ counts without and with drying. Whole-body glycolysis was calculated as the rate of increase in plasma ${ }^{3} \mathrm{H}_{2} \mathrm{O}$ concentration divided by the specific activity of plasma ${ }^{3} \mathrm{H}$-glucose as described previously (45). Whole-body glycogen synthesis was estimated by subtracting whole-body glycolysis from whole-body glucose uptake, assuming that glycolysis and glycogen synthesis account for the majority of insulinstimulated glucose uptake (46).

For the determination of individual tissue glucose uptake, tissue samples were homogenized, and the supernatants were subjected to an ionexchange column to separate tissue ${ }^{14} \mathrm{C}-2$-DG-6-phosphate (2-DG-6-P) from ${ }^{14} \mathrm{C}-2-\mathrm{DG}$. Tissue glucose uptake was calculated from the area under the curve of the plasma ${ }^{14} \mathrm{C}-2-\mathrm{DG}$ profile and muscle ${ }^{14} \mathrm{C}-2-\mathrm{DG}-6-\mathrm{P}$ content, as described previously (47).

Immunobistochemical analysis of pancreatic islet $\beta$ cell mass. Pancreata were fixed in Bouin's solution at room temperature overnight and embedded in paraffin, and $4-\mu \mathrm{m}$ sections were cut and mounted on glass slides. Sections were deparaffinized in xylene and rehydrated in graded ethanol solutions followed by water. Antigen retrieval was performed by heating the sections at $92-95^{\circ} \mathrm{C}$ for 15 minutes in $0.01 \mathrm{M}$ citrate buffer ( $\mathrm{pH} 6.0$ ). Nonspecific binding sites were blocked with $8 \%$ horse serum in PBS. Sections were incubated with anti-insulin monoclonal antibody (diluted 
1:5,000; Sigma-Aldrich) for 60 minutes at room temperature. Sections were washed in PBS and incubated with biotinylated goat anti-mouse $\operatorname{IgG}$ for 30 minutes at room temperature. Sections were washed in PBS, incubated with streptavidin-fluorescein isothiocyanate for 30 minutes at room temperature, and then washed with PBS. Coverslips were mounted with Vectashield (Vector Laboratories). A Nikon TE2000-U fluorescent microscope, a CCD camera (CoolSNAP $\mathrm{ES}_{\text {; }}$ Photometrics Inc.), and ImagePro Express software (version 5.1; Media Cybernetics) were used to visualize and evaluate stained sections.

Statistics. Data are expressed as mean \pm SEM. Statistical differences between 2 groups were determined by Student's $t$ test; differences between 3 or more groups were determined by ANOVA (Sigma-Aldrich). A $P$ value less than 0.05 was considered significant.

\section{Acknowledgments}

This work was supported by funds from the Department of Veterans Affairs Merit Review Program, by NIH grants DK 38079 (to R.V. Farese) and DK 30136 (to C.R. Kahn), and by Deutsche Forschungsgemeinschaft Sta314/2-1 and KE246/7-2 (to M. Leitges).

Received for publication January 4, 2007, and accepted in revised form May 8, 2007.

Address correspondence to: Robert V. Farese, ACOS-151, James A. Haley Veterans Hospital, 13000 Bruce B. Downs Blvd., Tampa, Florida 33612, USA. Phone: (813) 972-7662; Fax: (813) 972-7623; E-mail: rfarese@health.usf.edu.
1. Bandyopadhyay, G., et al. 2007. Activation of protein kinase $\mathrm{C}(\alpha, \beta$ and $\zeta)$ by insulin in 3T3/L1 cells. Transfection studies suggest a role for PKC- $\zeta$ in glucose transport. J. Biol. Chem. 272:2551-2558.

2. Standaert, M.L., et al. 1997. PKC- $\zeta$ as a downstream effector of PI 3-kinase during insulin stimulation in rat adipocytes. Potential role in glucose transport. J. Biol. Chem. 272:30075-30082.

3. Kotani, K., et al. 1998. Requirement of atypical protein kinase $\mathrm{C}$ lambda for insulin stimulation of glucose uptake but not for Akt activation in 3T3L1 adipocytes. Mol. Cell. Biol. 18:6971-6982.

4. Bandyopadhyay, G., et al. 2002. PKC- $\zeta$ mediates insulin effects on glucose transport in cultured preadipocyte-derived human adipocytes. J. Clin. Endocrinol. Metab. 87:716-723.

5. Sajan, M.P., Standaert, M.L., and Farese, R.V. 2006. Repletion of atypical protein kinase $C$ following RNAi-mediated depletion restores insulin-stimulated glucose transport. J. Biol. Chem. 281:17466-17473.

6. Bandyopadhyay, G., Kanoh, Y., Sajan, M.P., Standaert, M.L., and Farese, R.V. 2000. Effects of adenoviral gene transfer of wild-type, constitutively active, and kinase-defective protein kinase $\mathrm{C}-\lambda$ on insulin-stimulated glucose transport in L6 myotubes. Endocrinology. 141:4120-4127.

7. Condorelli, G., et al. 2001. Protein kinase C (PKC)alpha activation inhibits PKC-zeta and mediates the action of PED/PEA-15 on glucose transport in the L6 skeletal muscle cells. Diabetes. 50:1244-1250.

8. Ugi, S., et al. 2004. Protein phosphatase 2A negatively regulates insulin's metabolic signaling pathway by inhibiting Akt (protein kinase B) activity in 3T3-L1 adipocytes. Mol. Cell. Biol. 24:8778-8789.

9. Kohn, A.D., Summers, S.A., Birnbaum, M.J., and Roth, R.A. 1996. Expression of a constitutively active Akt Ser/Thr kinase in 3T3-L1 adipocytes stimulates glucose uptake and glucose transporter 4 translocation. J. Biol. Chem. 271:31372-31378.

10. Tanti, J., et al. 1997. Potential role of protein kinase $B$ in glucose transporter 4 translocation in adipocytes. Endocrinology. 138:2005-2009.

11. Wang, Q., et al. 1999. Protein kinase B/Akt participates in GLUT4 translocation by insulin in L6 myoblasts. Mol. Cell. Biol. 19:4008-4018.

12. Hill, M.M., et al. 1999. A role for protein kinase Bbeta/Akt2 in insulin-stimulated GLUT4 translocation in adipocytes. Mol. Cell. Biol. 19:7771-7781.

13. Cho, H., Thorvaldsen, J.L., Chu, Q., Feng, F., and Birnbaum, M.J. 2001. Akt1/PKBalpha is required for normal growth but dispensable for maintenance of glucose homeostasis in mice. J. Biol. Chem. 276:38349-38352.

14. Cho, H., et al. 2001. Insulin resistance and a diabetes mellitus-like syndrome in mice lacking the protein kinase Akt2 (PKB beta). Science. 292:1728-1731.

15. Matsumoto, M., et al. 2003. PKC $\lambda$ in liver mediates insulin-induced SREBP-1c expression and determines both hepatic lipid content and overall insulin sensitivity. J. Clin. Invest. 112:935-944.
doi:10.1172/JCI200318816.

16. Hashimoto, N., et al. 2005. PKC regulates glucoseinduced insulin secretion through modulation of gene expression in pancreatic $\beta$ cells. J. Clin. Invest. 115:138-145. doi:10.1172/JCI200522232.

17. Kim, Y.-B., Kotani, K., Ciaraldi, T.P., Henry, R.R., and Kahn, B.B. 2003. Insulin-stimulated protein kinase $\mathrm{C}$ lambda/zeta activity is reduced in skeletal muscle of humans with obesity and type 2 diabetes: reversal with weight reduction. Diabetes. 52:1935-1942.

18. Beeson, M., et al. 2004. Defective activation of protein kinase C-zeta in muscle by insulin and phosphatidylinositol-3,4,5-( $\left.\mathrm{PO}_{4}\right)_{3}$ in obesity and polycystic ovary syndrome. Metabolic Syndrome and Related Disorders. 2:49-56.

19. Vollenweider, P., Menard, B., and Nicod, P. 2002. Insulin resistance, defective insulin receptor substrate 2-associated phosphatidylinositol-3' kinase activation, and impaired atypical protein kinase $\mathrm{C}$ (zeta/lambda) activation in myotubes from obese patients with impaired glucose tolerance Diabetes. 51:1052-1059.

20. Beeson, M., et al. 2003. Activation of protein kinase $\mathrm{C}-\zeta$ by insulin and phosphatidylinositol-3,4,5$\left(\mathrm{PO}_{4}\right)_{3}$ is defective in muscle in type 2 diabetes and impaired glucose tolerance. Amelioration by rosiglitazone and exercise. Diabetes. 52:1926-1934.

21. Bandopadhyay, G., Yu, J.G., Ofrecio, J., and Olefsky, J.M. 2005. Increased p85/55/50 expression and decreased phosphotidylinositol 3-kinase activity in insulin-resistant human skeletal muscle. Diabetes. 54:2351-2359.

22. Bandyopadhyay, G., et al. 2004. Protein kinase C- $\lambda$ knockout in embryonic stem cells and adipocytes impairs insulin-stimulated glucose transport. Mol. Endocrinol. 18:373-383.

23. Kanoh, Y., et al. 2003. Defective activation of atypical protein kinase $\mathrm{C}$ zeta and lambda by insulin and phosphatidylinositol-3,4,5-( $\left.\mathrm{PO}_{4}\right)_{3}$ in skeletal muscles of rats following high-fat feeding and streptozotocin-induced diabetes. Endocrinology. 144:947-954

24. Standaert, M.L., et al. 2004. Insulin-induced activation of atypical protein kinase $\mathrm{C}$, but not protein kinase $\mathrm{B}$, is maintained in diabetic (ob/ob and Goto-Kakazaki) liver. Contrasting insulin signaling patterns in liver versus muscle define phenotypes of type 2 diabetic and high-fat-induced insulinresistant states. J. Biol. Chem. 279:24929-24934.

25. Yamauchi, T., et al. 2001. The fat-derived hormone adiponectin reverses insulin resistance associated with both lipoatrophy and obesity. Nat. Med. 7:941-946.

26. Ueki, K., et al. 2000. Restored insulin sensitivity in IRS-1-deficient mice treated by adenovirus-mediated gene therapy. J. Clin. Invest. 105:1437-1445.

27. Sajan, M.P., Standaert, M.L., Miura, A., Kahn, C.R., and Farese, R.V. 2004. Tissue-specific differences in activation of atypical protein kinase $\mathrm{C}$ and protein kinase $\mathrm{B}$ in muscle, liver, and adipocytes of insulin receptor substrate-1 knockout mice. Mol. Endocrinol. 18:2513-2521.

28. Valverde, A.M., et al. 2003. Molecular mechanisms of insulin resistance in IRS-2-deficient hepatocytes. Diabetes. 52:2239-2248.

29. Sarbassov, D.D., Guertin, D.A., Ali, S.M., and Sabatini, D.M. 2005. Phosphorylation and regulation of Akt/PKB by the rictor-mTOR complex. Science. 307:1098-1101.

30. Dong, L.Q., and Liu, F. 2005. PDK2: the missing piece in the receptor tyrosine kinase signaling pathway. Am. J. Physiol. Endocrinol. Metab. 289:E187-E196.

31. Zisman, A., et al. 2000. Targeted disruption of the glucose transporter 4 selectively in muscle causes insulin resistance and glucose intolerance. Nat. Med. 6:924-928.

32. Kim, J.K., et al. 2001. Glucose toxicity and the development of diabetes in mice with muscle-specific inactivation of GLUT4. J. Clin. Invest. 108:153-160. doi:10.1172/JCI200110294.

33. Minokoshi, Y., Kahn, C.R., and Kahn, B.B. 2003. Tissue-specific ablation of the GLUT4 glucose transporter or the insulin receptor challenges assumptions about insulin action and glucose homeostasis. J. Biol. Chem. 278:33609-33612.

34. Bruning, J.C., et al. 1998. A muscle-specific insulin receptor knockout exhibits features of the metabolic syndrome of NIDDM without altering glucose tolerance. Mol. Cell. 2:559-569.

35. Rossetti, L., et al. 1997. Peripheral but not hepatic insulin resistance in mice with one disrupted allele of the glucose transporter type 4 (GLUT4) gene. J. Clin. Invest. 100:1831-1839.

36. Li, J., Houseknecht, K.L., Steinbit, A.E., Katz, E.B., and Charron, M.J. 2000. Reduced glucose uptake precedes insulin signaling defects in adipocytes from heterozygous GLUT4 knockout mice. FASEBJ. 14:1117-1125.

37. Kotani, K., Peroni, O.D., Minokoshi, Y., Boss, O., and Kahn, B.B. 2004. GLUT4 glucose transporter deficiency increases hepatic lipid production and peripheral lipid utilization. J. Clin. Invest. 114:1666-1676. doi:10.1172/JCI200421341.

38. Karlsson, H.K.R., Ahlsen, M., Zierath, J.R., Wallberg-Nenriksson, H., and Koistenin, H.A. 2006. Insulin signaling and glucose transport in skeletal muscle from first-degree relatives of type 2 diabetic patients. Diabetes. 55:1283-1288.

39. Bjornholm, M., Kawano, Y., Lehtihet, M., and Zierath, J.R. 1997. Insulin receptor substrate-1 phosphorylation and phosphatidylinositol 3-kinase activity in skeletal muscle from NIDDM subjects after in vivo insulin stimulation. Diabetes. 46:524-527.

40. Brozinick, J.T., Roberts, B.R., and Dohm, D.L. 2003. Defective signaling through Akt- 2 and -3 but not Akt- 1 is reduced in insulin-resistant skeletal muscle. Diabetes. 52:935-941.

41. Krook, A., Roth, R.A., Jiang, X.J., and Zierath, J.R. 1998. Insulin-stimulated Akt activity is reduced in 
skeletal muscle from NIDDM subjects. Diabetes. 47:1281-1286

42. Karlsson, H.K.R., et al. 2005. Insulin-stimulated phosphorylation of the Akt substrate AS160 is impaired in skeletal muscle of type 2 diabetic subjects. Diabetes. 54:1692-1697.

43. Standaert, M.L., et al. 1999. Effects of knockout of the protein kinase $C$ beta gene on glucose transport and glucose homeostasis. Endocrinology.
140:4470-4477.

44. Casaubon, L., et al. 2006. Contrasting insulin dosedependent defects in activation of atypical protein kinase $\mathrm{C}$ and protein kinase $\mathrm{B} / \mathrm{Akt}$ in muscles of obese diabetic humans. Diabetologia. 49:3000-3008. 45. Samuel, V.T., et al. 2006. Targeting foxo 1 in mice using antisense oligonucleotide improves hepatic and peripheral insulin action. Diabetes. 55:2042-2050.
46. Rossetti, L., and Giaccari, A. 1990. Relative contribution of glycogen synthesis and glycolysis to insulin-mediated glucose uptake. A dose-response euglycemic clamp study in normal and diabetic rats. J. Clin. Invest. 85:1785-1792.

47. Youn, J.H., and Buchanan, T.A. 1993. Fasting does not impair insulin-stimulated glucose uptake but alters intracellular glucose metabolism in conscious rats. Diabetes. 42:757-763. 